\title{
In Silico Analysis of Some Phytochemicals as Potent Anti-tubercular Agents Targeting Mycobacterium tuberculosis RNA Polymerase and InhA Protein
}

Md Emran ${ }^{1}$, Md. Mofijur Rahman ${ }^{1}$, Afroza Khanam Anika ${ }^{1}$, Sultana Hossain Nasrin ${ }^{1}$, Abu Tayab Moin ${ }^{2 *}$

${ }^{1}$ Department of Biochemistry and Biotechnology, Faculty of Basic Medical and pharmaceutical Sciences, University of Science and Technology Chittagong, Chattogram, Bangladesh

${ }^{2}$ Department of Genetic Engineering and Biotechnology, Faculty of Biological Sciences University of Chittagong, Chattogram, Bangladesh

\section{For Correspondence:}

Abu Tayab Moin

Email: tayabmoin786@gmail.com

\begin{abstract}
Tuberculosis (TB) is a contagious disease, caused by Mycobacterium tuberculosis (MTB) that has infected and killed a lot of people in the past. At present treatments against TB are available at a very low cost. Since these chemical drugs have many adverse effects on health, more attention is now given on the plant-derived phytochemicals as potential agents to fight against $\mathrm{TB}$. In this study, 5 phytochemicals, 4-hydroxybenzaldehyde, benzoic acid, bergapten, psoralen, and phydroxybenzoic acid, are selected to test their potentiality, safety, and efficacy against two
\end{abstract}


potential targets, the MTB RNA polymerase and enoyl-acyl carrier protein (ACP) reductase, the InhA protein, using various tools of in silico biology. The molecular docking experiment, druglikeness property test, ADME/T-test, P450 SOM prediction, pharmacophore mapping, and modeling, solubility testing, DFT calculations, and PASS prediction study had confirmed that all the molecules had the good potentiality to inhibit the two targets. However, two agents, 4hydroxybenzaldehyde and bergapten were considered as the best agents among the five selected agents and they also showed far better results than the two currently used drugs, that function in these pathways, rifampicin (MTB RNA polymerase) and isoniazid (InhA protein). These two agents can be used effectively to treat tuberculosis.

Keywords: Tuberculosis, 4-hydroxybenzaldehyde, bergapten, molecular docking.

\section{Introduction}

Tuberculosis (TB) is an ancient disease that plagued mankind many times in the past. It was responsible for many great epidemics. Mycobacterium tuberculosis (MTB) is the bacteria that is responsible for tuberculosis disease. This bacteria may have killed more people than any other microbial pathogens (Daniel, 2006). However, at present, tuberculosis is a preventable as well as a curable disease, which is possible at a very low cost. Tuberculosis is a highly contagious disease that can transmit via cough, spit, and sneezes of the infected person. MTB primarily infects the 
lungs (. Grange and Zumla, 2002; Sepkowitz, 1996, Shah et al., 2015). If the disease is found in the lungs, then it is called pulmonary TB. However, TB can be found at other locations of the body. Such TB is called extra-pulmonary TB. Several antibiotics are used to fight against MTB. However, a new TB has emerged in recent years, which is resistant to multiple drugs that are commonly used in TB treatment. This new TB is called multidrug-resistant tuberculosis (MDRTB). At present, rifampicin, isoniazid, pyrazinamide, and ethambutol are used all together to treat tuberculosis. However, as the MDR-TB is found to be resistant to multiple drugs that are used in the treatment of normal TB, other sets of drugs are used to treat the MDR-TB (Sreeramareddy et al., 2008; McIlleron et al., 2006; Ettehad et al., 2012). Rifampicin inhibits bacterial growth by inhibiting the RNA polymerase enzyme. RNA polymerase enzyme is responsible for synthesizing an RNA strand from a DNA strand by the process known as transcription (Figure 01). Ethambutol exerts its effects by inhibiting the transfer of mycolic acids into the cell wall of MTB as well as by changing the lipid metabolism of the bacteria. Pyrazinamide disrupts the membrane energetics and membrane transport. Thus, pyrazinamide shortens TB therapy (Rastogi and David, 1993; Zhang et al., 2003). Isoniazid, a drug used for treating TB, inhibits bacterial growth by inhibiting InhA protein, an enoyl-acyl carrier protein (ACP) reductase. The InhA protein is involved in the type II fatty acid biosynthesis pathway as well as mycolic acid synthesis which is an essential component of the bacterial cell membrane (Ducasse-Cabanot et al., 2004; He et al., 2007). In the mycolic acid synthesis pathway, two types of fatty acid synthase (FAS) enzymes are involved: FAS I and FAS II. The FAS I enzyme generates the starting material of the mycolic acid synthesis, acetyl-CoA. The acyl-CoA is converted to 3-ketoacyl-ACP by Kas III enzyme (betaketoacyl-ACP synthase III). The 3-ketoacyl-ACP then enters into a cyclic reaction catalyzed by the FAS II enzyme. 3-ketoacyl-ACP is converted into 3R-hydroxyacyl-ACP by beta-ketoacyl- 
ACP reductase enzyme, MabA. The 3R-hydroxyacyl-ACP is later converted to trans-2-enol-ACP by beta-hydroxyacyl-ACP dehydratases, HadAB and HadBC. Next, the trans-2-enol-ACP is converted to acetyl-ACP by the InhA protein. The acyl-ACP can be converted to either 3-ketoacylACP to start the cycle again (catalyzed by beta-keto-acyl-ACP synthetases, KasA and KasB proteins), or it can be converted to higher chained ACP like C18-ACP and later the C18-ACP forms ever higher chained ACP like C48-ACP to C62-ACP. Moreover, FAS I also generates carboxylated C26-CoA, which together with C48-C62-ACP, undergoes condensation/reduction reaction and forms mycolic acid (Figure 02). The inhibitors of InhA enzyme acts by inhibiting InhA and thus prevents the mycolic acid synthesis (Dong et al., 2015; Molle et al., 2010; Carel et al., 2014).

Computational methods are now extensively used in drug R\&D processes. Such virtual screening methods reduce both time and cost of the drug discovery and development processes. Computational simulation tools are used in designing more than 50 drugs to this date and many of them have received FDA approval. Molecular docking predicts the interaction, pose, and conformation of a ligand within the binding site of a target molecule. After estimating the interactions, the software assigns scores to each of the bound ligands with a specified algorithm which reflects the binding affinity. Lowest score of binding (lowest docking score) represents the most appreciable interaction between the ligand and receptor (Zoete et al., 2009; SchneidmanDuhovny et al., 2004).

Natural agents from plants like 4-hydroxybenzaldehyde, benzoic acid, bergapten, Psoralen, phydroxybenzoic acid and many other compounds are proved to exhibit anti-tuberculosis properties in various studies (Chen et al., 2005; Lim, 2014; Dokorou et al., 2004; Chiang et al., 2010; Chen, 2007). The agents can be extracted from a variety of plant sources (Table 01). In this experiment, 
the two commercially available and mostly used drugs, rifampicin against MTB RNA polymerase and isoniazid against the InhA protein, were used as controls. The mentioned five ligands: 4hydroxybenzaldehyde, benzoic acid, bergapten, psoralen and p-hydroxybenzoic acid, are used to dock against the MTB RNA polymerase and the InhA protein to test their efficacy and potentiality against the enzymes. Later, the two best ligands, each against one enzyme, were determined by analyzing the various tests that are conducted in the experiment and the two ligands were compared with the control to test their efficiency to inhibit TB.

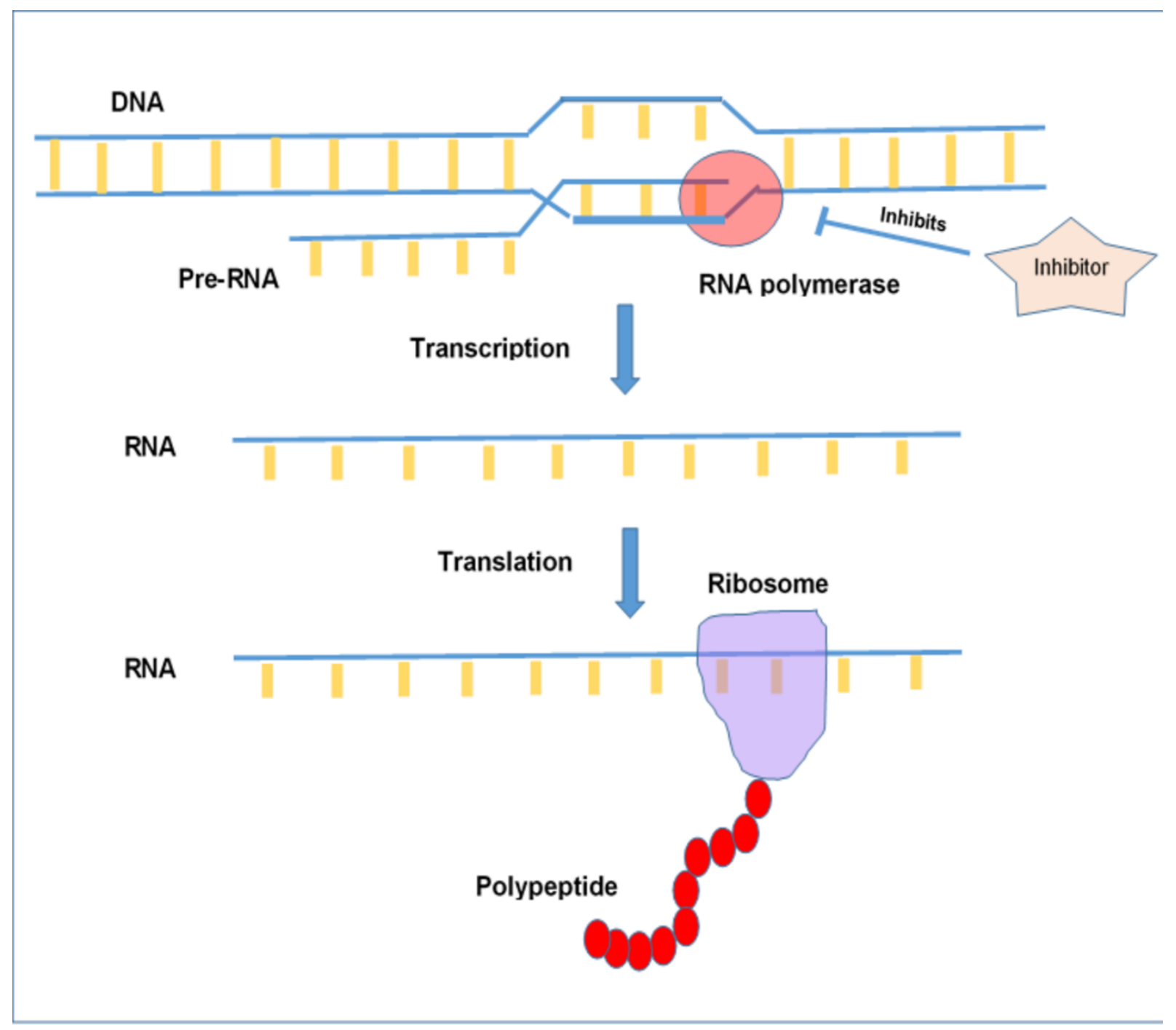

Figure 01. RNA polymerase is the enzyme that is responsible for the transcription of DNA to mRNA. Inhibiting RNA polymerase would result in disruption of transcription, which can be lethal to the cell and the organism. 


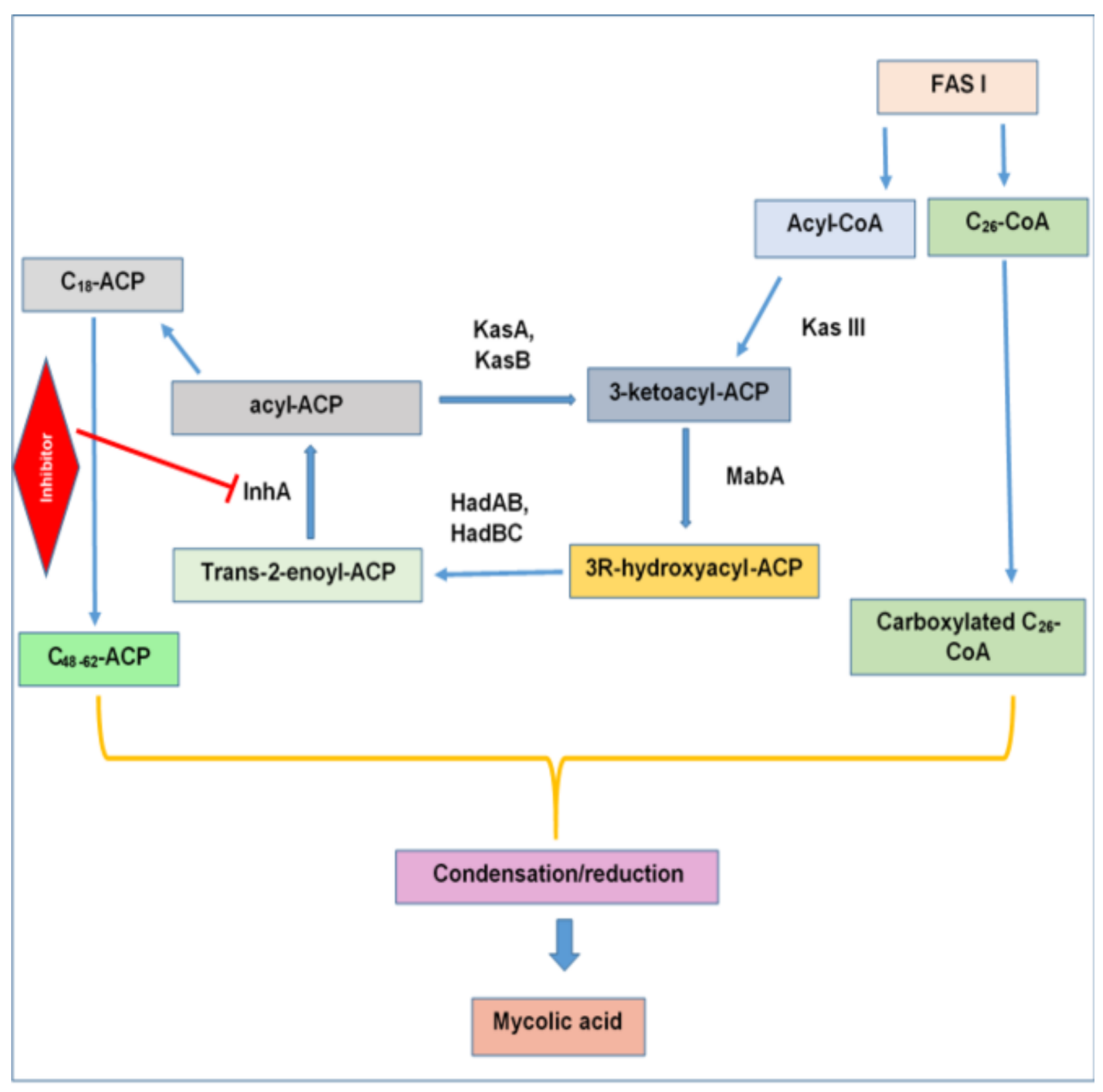

Figure 02. The involvement of InhA protein in the mycolic acid synthesis pathway. Here, FAS I and FAS II are fatty acid synthase I and II, respectively, MabA is a beta-ketoacyl-acyl carrier protein (ACP) reductase, HadAB and HadBC are beta-ketoacyl_ACP dehydratases, Kas A, Kas B and Kas III are beta-keto-acyl-ACP synthetases. Inhibitors of InhA protein can interfere with the formation of mycolic acid, which an important component of MTB, thus inhibiting the MTB growth. 
Table 01. Table showing anti-tuberculosis agents with their respective plant sources.

\begin{tabular}{|l|l|l|}
\hline No & Name of the anti-tuberculosis agent & Plant source \\
\hline \hline 01 & 4-hydroxybenzaldehyde & Cinnamomum kotoense \\
\hline 02 & Benzoic acid & Hibiscus taiwanensis \\
\hline 03 & Bergapten & Fatoua pilosa \\
\hline 04 & Psoralen & Fatoua pilosa \\
\hline 05 & p-hydroxybenzoic acid & Microtropis fokienensis \\
\hline
\end{tabular}

\section{Materials and Methods}

Ligand preparation, Grid generation and Glide docking, 2D representations of the best pose interactions between the ligands and their respective receptors were obtained using MaestroSchrödinger Suite 2018-4 and the 3D representations of the best pose interactions between the ligands and their respective receptors were visualized using Discovery Studio Visualizer (Schrödinger Release 2015-1, 2015; Visualizer, 2017). The 2D structures of ligands were downloaded from PubChem in SDF format (www.pubchem.ncbi.nlm.nih.gov) and the two receptors were downloaded from protein data bank (www.rcsb.org). 


\subsection{Protein Preparation}

Three-dimensional structure of MTB RNA polymerase (PDB ID: 6M7J) and InhA protein (PDB ID: 2NSD) were downloaded in PDB format from protein data bank (www.rcsb.org). The proteins were then prepared and refined using the Protein Preparation Wizard in Maestro Schrödinger Suite 2018-4 (Sastry et al., 2013). Bond orders were assigned and hydrogens were added to heavy atoms. Selenomethionines were converted to methionines as well as all the waters were deleted. Finally, the structure was optimized and then minimized using force field OPLS_2005.

\subsection{Ligand Preparation and Receptor Grid Generation}

The 2D conformations of 4-hydroxybenzaldehyde (PubChem CID: 126), Benzoic acid (PubChem CID: 243), Bergapten (PubChem CID: 2355), Psoralen (PubChem CID: 6199) and phydroxybenzoic acid (PubChem CID: 135) were downloaded (sequentially) from PubChem (www.pubchem.ncbi.nlm.nih.gov). The 3D conformers of the ligands were visualized by the Galaxy 3D Structure Generator v2018.01-beta tool of online server Molinspiration chemoinformatics (https://www.molinspiration.com/). These structures were then prepared using the LigPrep function of Maestro Schrödinger Suite 2018-4 (LigPrep, Schrödinger, 2014).

Grid usually confines the active site to shortened specific areas of the receptor protein for the ligand to dock specifically. In Glide, a grid was generated using default Van der Waals radius scaling factor 1.0 and charge cutoff 0.25 which was then subjected to the OPLS_2005 force field. A cubic box was generated around the active site (reference ligand active site). Then the grid box volume was adjusted to $15 \times 15 \times 15$ for the docking test.

\subsection{Glide Standard Precision (SP) Ligand Docking and MM-GBSA Prediction}

SP adaptable glide docking was carried out using Glide in Maestro Schrödinger Suite 2018-4. The Van der Waals radius scaling factor and charge cutoff was set to 0.80 and 0.15 respectively for all 
the ligand molecules. The ligand with the lowest glide docking score was considered as the best ligand. The 2D and 3D pose interactions between the ligands and receptor were visualized by Maestro Schrödinger Suite 2018-4 and the interaction of the ligand molecule with various types of amino acids as well as their bonds was analyzed by Discovery Studio Visualizer. The molecular mechanics- generalized born and surface area (MM-GBSA) tool was used to determine the $\triangle$ GBind scores. The MM-GBSA study was carried out using Maestro-Schrödinger Suite 2018-4.

\subsection{Ligand Based Drug Likeness Property and ADME/Toxicity Prediction}

The molecular structures of every ligand were analyzed using the SWISSADME server (http://www.swissadme.ch/) to confirm whether they obey Lipinki's rule of five or not, along with some other properties. Various physicochemical properties of ligand molecules were calculated using OSIRIS Property Explorer (https://www.organic-chemistry.org/prog/peo/). The druglikeness properties of the selected ligand molecules were analyzed using the SWISSADME server (http://www.swissadme.ch/) as well as the OSIRIS Property Explorer (https://www.organicchemistry.org/prog/peo/) (Organic Chemistry Portal. https://www.organicchemistry.org/prog/peo. 10/10/2019. Accessed: 09 August, 2019).

The ADME/T for each of the ligand molecules was carried out using online based servers, admetSAR (http://lmmd.ecust.edu.cn/admetsar2/) and ADMETlab (http://admet.scbdd.com/) to predict their various pharmacokinetic and pharmacodynamic properties. Both admetSAR and ADMETlab servers are comprehensive tools to determine the absorption, distribution, metabolism, excretion and toxicity of various chemical compounds (Cheng et al., 2014; Dong et al., 2018).

\subsection{P450 Site of Metabolism (SOM) Prediction}

The P450 Site of Metabolism (SOM) of the selected ligand molecules was determined by an online tool, RS-WebPredictor 1.0 (http://reccr.chem.rpi.edu/Software/RS-WebPredictor/) (Zaretzki et al., 
2012). The potential sites of metabolism on the selected ligands were determined for nine isoforms of the CYP 450 enzyme family: CYPs 1A2, 2A6, 2B6, 2C19, 2C8, 2C9, 2D6, 2E1 and 3A4.

\subsection{Pharmacophore Modelling}

The pharmacophore modelling of the 5 ligands was carried out using the Phase pharmacophore perception engine of Maestro-Schrödinger Suite 2018-4. The pharmacophore modelling was done manually. To carry out the process, the radii sizes were kept as the van der Waals radii of receptor atoms, the radii scaling factor was kept at 0.50 , receptor atoms whose surfaces are within $2.00 \AA$ of the ligand surface were ignored and the volume shell thickness was limited to $5.00 \AA$. The 2D and 3D pharmacophore modelling were carried out for all the ligand molecules.

\subsection{Solubility Prediction}

The solubility testing of the five ligands was performed using the QikProp wizard of MaestroSchrödinger Suite 2018-4. In solubility prediction, the solubility of the selected ligands were determined in various interfaces like hexadecane/gas interface, octanol/gas interface, octanol/water interface etc.

\subsection{DFT Calculation}

Minimized ligand structures obtained from LigPrep were used for DFT calculation using the Jaguar panel of Maestro Schrödinger Suite v11.4 using Becke's three-parameter exchange potential and Lee-Yang-Parr correlation functional (B3LYP) theory with 6-31G* basis set (Lee et al., 1988; Becke, 1988). Quantum chemical properties such as surface properties (MO, density, potential) and Multipole moments were calculated along with HOMO (Highest Occupied Molecular Orbital) and LUMO (Lowest Unoccupied Molecular Orbital) energy. Then the global frontier orbital was analyzed and the hardness $(\boldsymbol{\eta})$ and softness $(\mathbf{S})$ of selected molecules were 
calculated using the following equation as per Parr and Pearson interpretation and Koopmans theorem (Pearson, 1986; Parr et al., 1989).

$\eta=($ HOMOE-LUMOE)/2,

$\mathbf{S}=\mathbf{1} / \eta$

\subsection{PASS (Prediction of Activity Spectra for Substances) Prediction Study}

The PASS (Prediction of Activity Spectra for Substances) prediction was carried out for only the two best-selected ligands that showed the best result in inhibiting their respective receptors, MTB RNA polymerase and InhA protein. PASS prediction was conducted by using the PASSWay2Drug server (http://www.pharmaexpert.ru/passonline/) by using canonical SMILES from PubChem server (https://pubchem.ncbi.nlm.nih.gov/) (Filimonov et al., 2014). To carry out PASS prediction, $\mathrm{Pa}$ (probability "to be active") was kept greater than 70\%, since the $\mathrm{Pa}>70 \%$ threshold gives highly reliable prediction (Geronikaki et al., 1999). In the PASS prediction study, both the possible biological activities and the possible adverse effects of the selected ligands were predicted. The LD50 and Toxicity class were predicted using ProTox-II server (http://tox.charite.de/protox_II/) (Drwal et al., 2014).

\section{Results}

\subsection{Molecular Docking Study and Ramachandran Plot Analysis}

All the selected ligand molecules and the controls were docked successfully with their target receptors, MTB RNA polymerase and MTB InhA protein. The controls, rifampicin and isoniazid generated docking scores of $-4.813 \mathrm{Kcal} / \mathrm{mol}$ (with MTB RNA polymerase) and $-6.018 \mathrm{Kcal} / \mathrm{mol}$ (with the InhA protein), respectively. 4-hydroxybenzaldehyde generated docking scores of -6.062 
$\mathrm{Kcal} / \mathrm{mol}$ with RNA polymerase and $-7.161 \mathrm{Kcal} / \mathrm{mol}$ with InhA protein. Benzoic acid showed docking scores of $-5.383 \mathrm{Kcal} / \mathrm{mol}$ with RNA polymerase and $-7.302 \mathrm{Kcal} / \mathrm{mol}$ with InhA protein. Bergapten generated docking scores of $-5.290 \mathrm{Kcal} / \mathrm{mol}$, when docked against RNA polymerase and $-8.068 \mathrm{Kcal} / \mathrm{mol}$ with InhA protein. Psoralen generated docking scores of $-5.731 \mathrm{Kcal} / \mathrm{mol}$ with RNA polymerase and $-7.102 \mathrm{Kcal} / \mathrm{mol}$, when docked against InhA protein. And phydroxybenzoic acid generated docking scores of $-4.617 \mathrm{Kcal} / \mathrm{mol}$ with RNA polymerase and $7.538 \mathrm{Kcal} / \mathrm{mol}$ with InhA protein. From the docking study, it is clear that 4-hydroxybenzaldehyde generated the lowest score of $-6.062 \mathrm{Kcal} / \mathrm{mol}$ with RNA polymerase and bergapten generated the lowest score of $-8.068 \mathrm{Kcal} / \mathrm{mol}$ with InhA protein.

On the other hand, all the ligands and the controls also gave successful results in the MM-GBSA study. In the MM-GBSA study, the $\triangle$ GBind score was determined. Rifampicin and isoniazid generated $\Delta$ GBind scores of $-34.317 \mathrm{Kcal} / \mathrm{mol}$ and $-29.728 \mathrm{Kcal} / \mathrm{mol}$, respectively. 4hydroxybenzaldehyde generated $\Delta$ GBind scores of $-53.070 \mathrm{Kcal} / \mathrm{mol}$ with RNA polymerase and $34.240 \mathrm{Kcal} / \mathrm{mol}$ with InhA protein. Benzoic acid showed $\Delta$ GBind scores of $-40.810 \mathrm{Kcal} / \mathrm{mol}$ with RNA polymerase and $-40.440 \mathrm{Kcal} / \mathrm{mol}$ with $\mathrm{InhA}$ protein. Bergapten generated $\Delta$ GBind scores of $-42.390 \mathrm{Kcal} / \mathrm{mol}$ and $-57.590 \mathrm{Kcal} / \mathrm{mol}$ with $\mathrm{Inh} A$ protein. Psoralen generated $\Delta$ GBind scores of $-43.150 \mathrm{Kcal} / \mathrm{mol}$ with RNA polymerase and $-55.330 \mathrm{Kcal} / \mathrm{mol}$ with InhA protein. And p-hydroxybenzoic acid generated $\Delta$ GBind scores of $-37.53 \mathrm{Kcal} / \mathrm{mol}$ with RNA polymerase and $45.740 \mathrm{Kcal} / \mathrm{mol}$ with InhA protein. The MM-GBSA study confirmed that 4hydroxybenzaldehyde also generated the lowest $\Delta$ GBind score of $-53.070 \mathrm{Kcal} / \mathrm{mol}$ like the docking study with RNA polymerase as well as bergapten generated the lowest $\Delta$ GBind score of $-57.590 \mathrm{Kcal} / \mathrm{mol}$ with InhA protein. 
Bergapten formed the highest number of hydrogen bonds with both RNA polymerase (05) as well as InhA protein (08). Bergapten also interacted with the highest number of amino acids within the binding pocket of RNA polymerase. It interacted with 05 amino acids: Arg 421, Val 422, Leu 1089, Ile 1253 and Gly 1069, when docked against MTB RNA polymerase. On the other hand, it also interacted with 07 amino acids within the bonding pocket of InhA protein: Lys 165, Gly 96, Ile 194, Gly 192, Ala 191, Ile 21 and Met 147. 4-hydroxybenzaldehyde also interacted with 07 amino acids when docked against InhA protein: Met 147, Lys 165, Ile 194, Ile 21, Pro 193, Gly 192 and Ala 191. The docking scores, glide energy and glide ligand efficiency of the controls are listed in Table 02. The docking scores, glide energies, glide ligand efficiency scores, $\Delta$ GBind scores, number of hydrogen bonds, interacting amino acids as well as different types of bonds and their distances are listed in Table 03. Figure 03, Figure 04 and Figure 05 illustrate the 2D and 3D representations of the best interaction between the ligands and receptors as well as the various amino acids that take part in the interaction. 
Table 02. Results of molecular docking between the controls and their receptors.

\begin{tabular}{|c|c|c|c|c|c|}
\hline $\begin{array}{l}\text { Name of the } \\
\text { control }\end{array}$ & $\begin{array}{l}\text { Name of the } \\
\text { receptors }\end{array}$ & $\begin{array}{l}\text { Docking score/ } \\
\text { binding energy } \\
\text { (Kcal/mol) }\end{array}$ & $\begin{array}{l}\text { Glide energy } \\
\text { (Kcal/mol) }\end{array}$ & $\begin{array}{l}\text { Glide ligand } \\
\text { efficiency } \\
\text { (Kcal/mol) }\end{array}$ & $\begin{array}{l}\text { MM-GBSA } \\
\left(\Delta G_{\text {Bind }} \text { Score }\right. \\
\text { Kcal } / \text { mol })\end{array}$ \\
\hline $\begin{array}{l}\text { Rifampicin } \\
\text { (PubChem CID: } \\
\text { 135398735) } \\
\text { (Control-1) }\end{array}$ & $\begin{array}{l}\text { MTB RNA } \\
\text { Polymerase } \\
\text { (PDB ID: } \\
6 \mathrm{M} 7 \mathrm{~J})\end{array}$ & $\begin{array}{l}-4.813 \\
\end{array}$ & $\begin{array}{c}-25.247 \\
\end{array}$ & -0.503 & -34.317 \\
\hline $\begin{array}{l}\text { Isoniazid } \\
\text { (PubChem CID: } \\
\text { 3767) (Control-2) }\end{array}$ & $\begin{array}{l}\text { InhA protein } \\
(2 \mathrm{NSD})\end{array}$ & -6.018 & -29.728 & -0.602 & -25.120 \\
\hline
\end{tabular}

Table 03. Results of molecular docking between ligands and receptors. All the selected ligands were docked successfully against the MTB RNA polymerase and InhA protein.

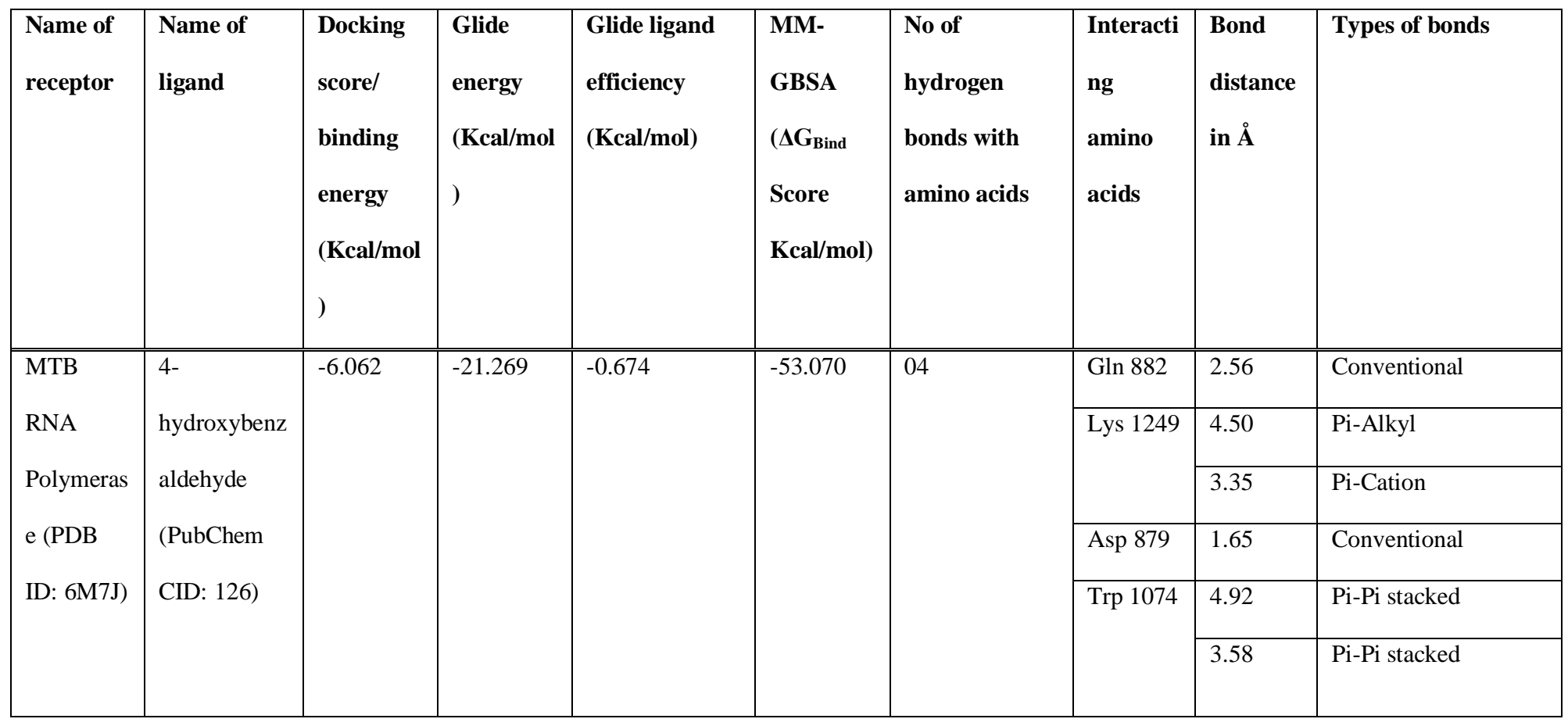




\begin{tabular}{|c|c|c|c|c|c|c|c|c|}
\hline \multirow{6}{*}{$\begin{array}{l}\text { Benzoic acid } \\
\text { (PubChem } \\
\text { CID: 243) }\end{array}$} & \multirow[t]{6}{*}{-5.383} & \multirow[t]{6}{*}{-21.786} & \multirow[t]{6}{*}{-0.598} & \multirow[t]{6}{*}{-40.810} & \multirow[t]{6}{*}{02} & Gly 408 & 2.72 & Conventional \\
\hline & & & & & & \multirow[t]{2}{*}{ Ala 1224} & 2.15 & Conventional \\
\hline & & & & & & & 4.28 & Pi-Alkyl \\
\hline & & & & & & Leu & 5.28 & Pi-Alkyl \\
\hline & & & & & & 1221 & & \\
\hline & & & & & & Ile 1253 & 5.39 & Pi-Alkyl \\
\hline \multirow{6}{*}{$\begin{array}{l}\text { Bergapten } \\
\text { (PubChem } \\
\text { CID: 2355) }\end{array}$} & \multirow[t]{6}{*}{-5.290} & \multirow[t]{6}{*}{-30.331} & \multirow[t]{6}{*}{-0.331} & \multirow[t]{6}{*}{-42.390} & \multirow[t]{6}{*}{05} & Arg 421 & 2.19 & Conventional \\
\hline & & & & & & Val 422 & 2.78 & Conventional \\
\hline & & & & & & Leu & 5.02 & Pi-Alkyl \\
\hline & & & & & & 1089 & 4.93 & Pi-Alkyl \\
\hline & & & & & & Ile 1253 & 5.35 & Pi-Alkyl \\
\hline & & & & & & Gly 1069 & 2.55 & Carbon \\
\hline \multirow{9}{*}{$\begin{array}{l}\text { Psoralen } \\
\text { (PubChem } \\
\text { CID: 6199) }\end{array}$} & \multirow[t]{9}{*}{-5.731} & \multirow[t]{9}{*}{-26.147} & \multirow[t]{9}{*}{-0.409} & \multirow[t]{9}{*}{-43.150} & \multirow[t]{9}{*}{04} & \multirow{3}{*}{$\begin{array}{l}\text { Leu } \\
1089\end{array}$} & 4.23 & Pi-Alkyl \\
\hline & & & & & & & 4.26 & Pi-Alkyl \\
\hline & & & & & & & 5.38 & Pi-Alkyl \\
\hline & & & & & & Cys & 5.33 & Pi-Alkyl \\
\hline & & & & & & 1073 & & \\
\hline & & & & & & Gln 1069 & 2.66 & Carbon \\
\hline & & & & & & Lys 420 & 2.06 & Conventional \\
\hline & & & & & & Gly 419 & 2.71 & Carbon \\
\hline & & & & & & & 2.84 & Conventional \\
\hline \multirow{4}{*}{$\begin{array}{l}\text { p- } \\
\text { hydroxybenz } \\
\text { oic acid }\end{array}$} & \multirow[t]{6}{*}{-4.617} & \multirow[t]{6}{*}{-24.020} & \multirow[t]{6}{*}{-0.462} & \multirow[t]{6}{*}{-37.530} & \multirow[t]{6}{*}{03} & Ile 1253 & 2.14 & Conventional \\
\hline & & & & & & $\begin{array}{l}\text { Leu } \\
1089\end{array}$ & 2.90 & Pi-Sigma \\
\hline & & & & & & Lys 420 & 5.26 & Pi-Alkyl \\
\hline & & & & & & & 2.47 & Pi-Donor \\
\hline \multirow{2}{*}{ CID: 135) } & & & & & & \multirow[t]{2}{*}{ Gly 419} & 2.69 & Carbon \\
\hline & & & & & & & 2.43 & Conventional \\
\hline \multirow{2}{*}{$\begin{array}{l}\text { 4- } \\
\text { hydroxybenz }\end{array}$} & \multirow[t]{2}{*}{-7.161} & -26.863 & -0.796 & -34.240 & 04 & Lys 165 & 2.07 & Conventional \\
\hline & & & & & & Met 147 & 5.41 & Pi-Alkyl \\
\hline
\end{tabular}




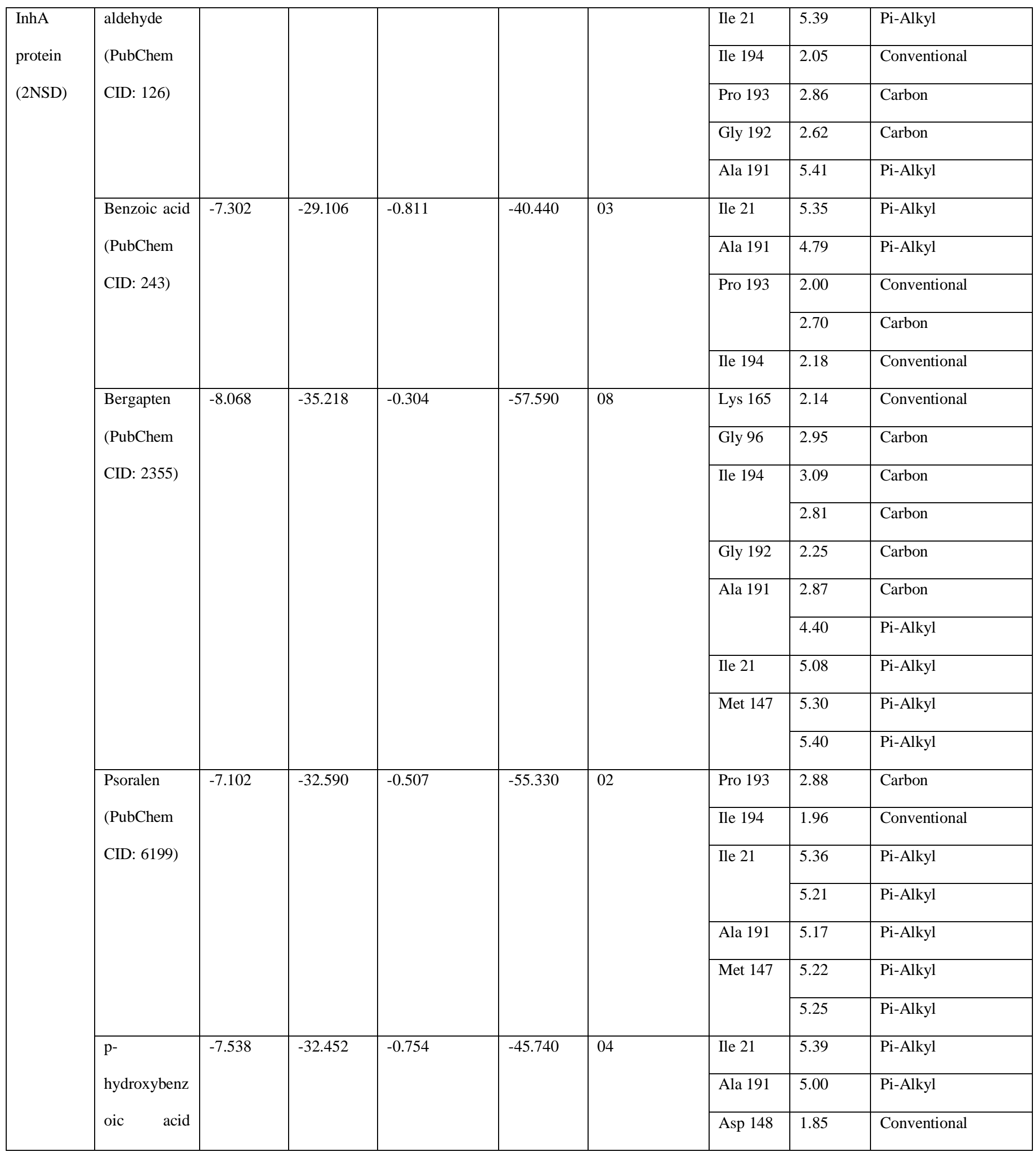




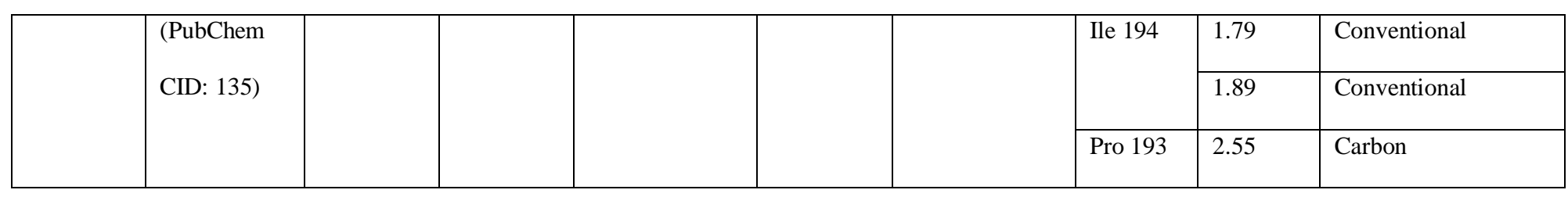

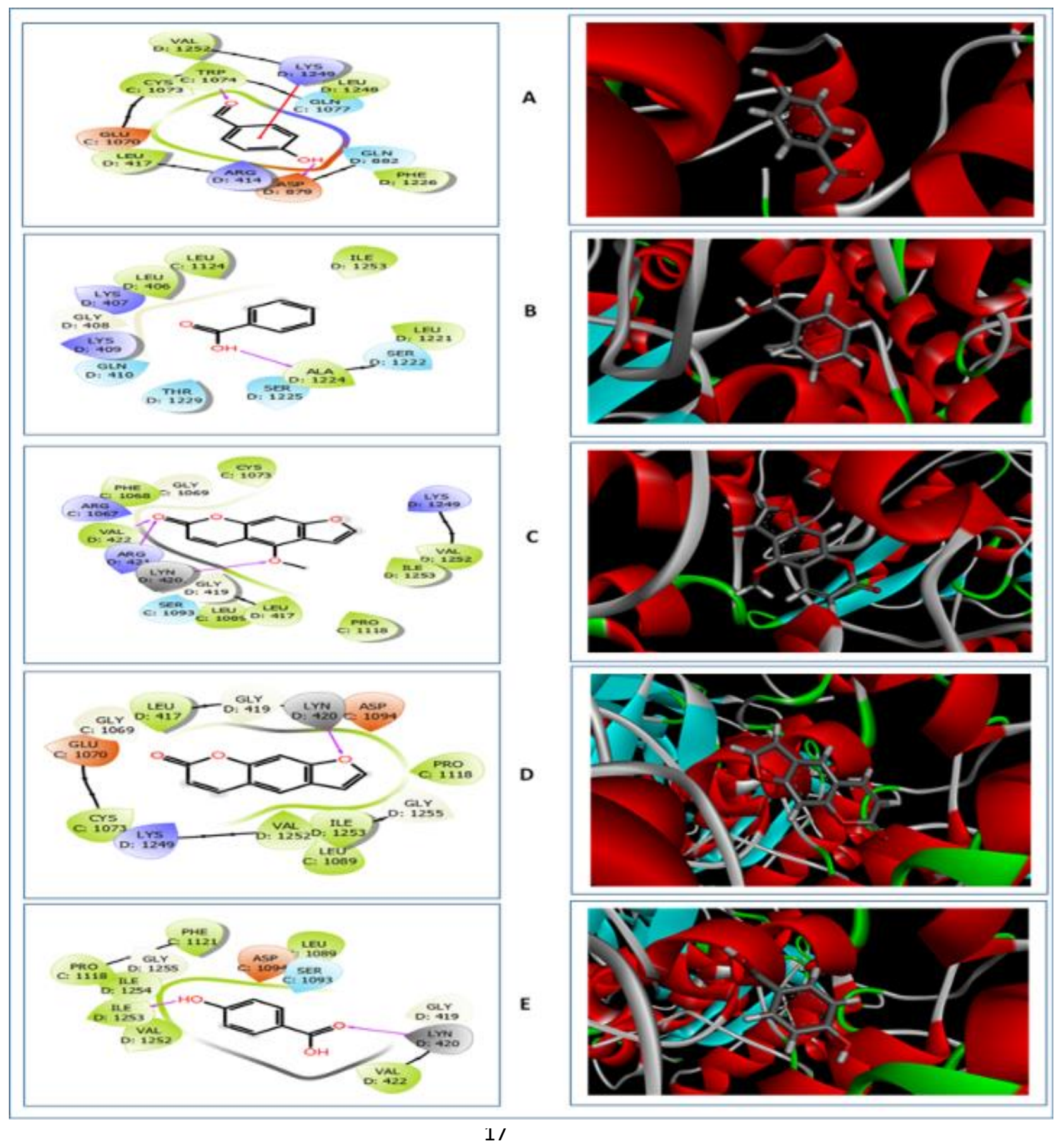


Figure 03. 2D (left) and 3D (right) representations of the best pose interactions between the ligands and the receptor, MTB RNA polymerase. A. interaction between 4-hydroxybenzaldehyde and RNA polymerase, B. interaction between benzoic acid and RNA polymerase, C. interaction between bergapten and RNA polymerase, D. interaction between psoralen and RNA polymerase, E. interaction between p-hydroxybenzoic acid and RNA polymerase. Colored spheres indicates the type of residue in the target: Red-Negatively charged (Asp, Glu), Blue- Polar (Ser, Thr, Gln), Green-Hydrophobic (Ala, Leu, Val, Ile, Trp, Phe, Cys, Pro), Light Purple-Basic (Lys, Arg), GrayWater molecules, Darker gray-metal atom, Light Yellow- Glycine, Deep Purple- Unspecified molecules and the Grayish circles represent Solvent exposure. Interactions are shown as colored lines- Solid pink lines with arrow- H-bond in target (backbone), Dotted pink lines with arrow- Hbond between receptor and ligand (side-chain), Solid pink lines without arrow- Metal coordination, Green line- Pi-Pi stacking interaction, Green dotted lines- Distances, Partially blue and red colored lines- Salt bridges. Ligands exposed to solvent are represented by the grey sphere. The colored lines show the protein pocket for the ligand according to the nearest atom. Interruptions of the lines indicate the opening of the pocket. In the 3D representations, the proteins are represented in the Solid ribbon model and the ligands are represented in Stick model. 

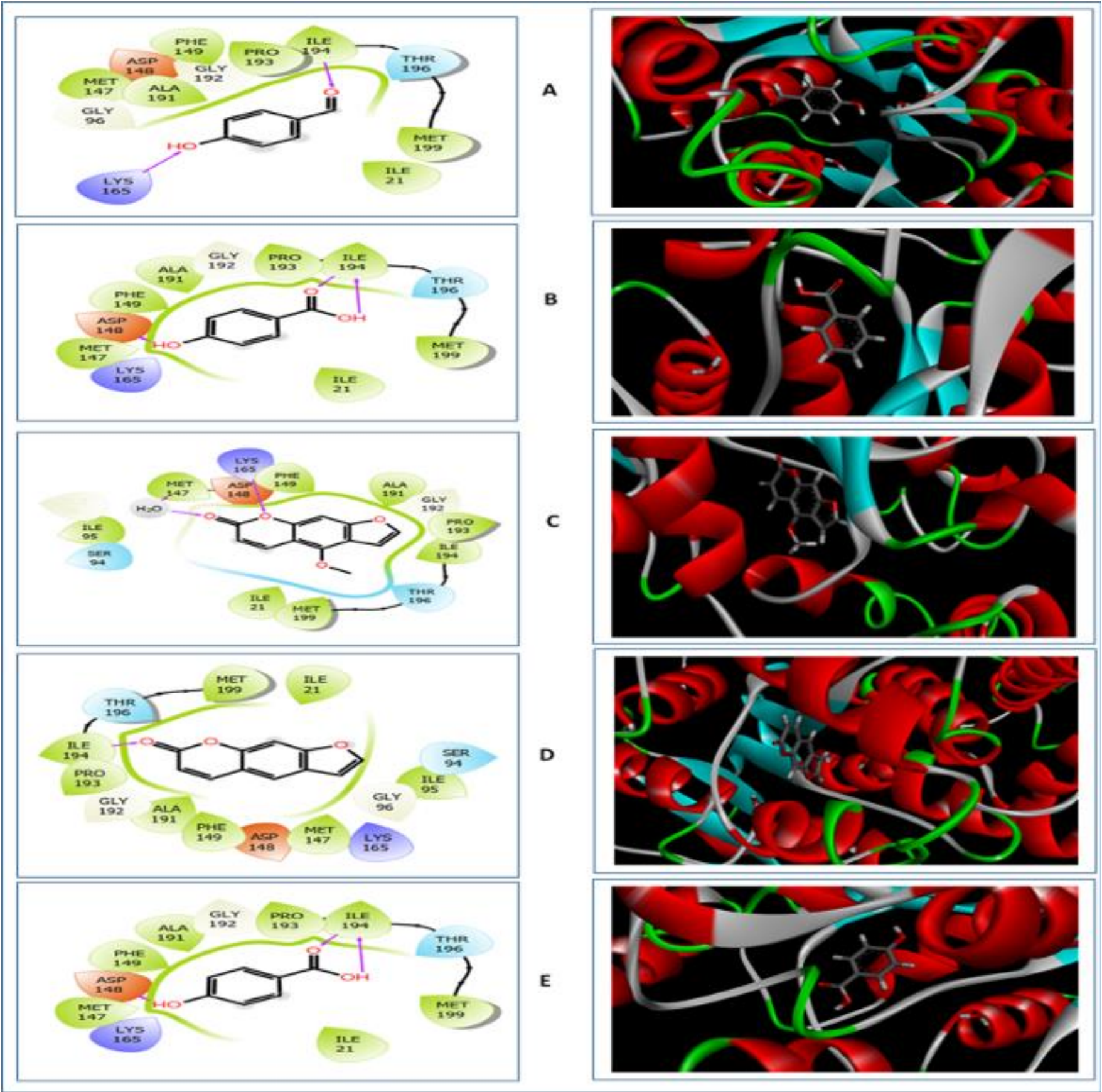
Figure 04. 2D (left) and 3D (right) representations of the best pose interactions between the ligands and the receptor, InhA protein A. interaction between 4-hydroxybenzaldehyde and InhA protein, B. interaction between benzoic acid and InhA protein, C. interaction between bergapten and InhA protein, D. interaction between psoralen and InhA protein, E. interaction between phydroxybenzoic acid and InhA protein. Colored spheres indicate the type of residue in the target: Red-Negatively charged (Asp), Blue- Polar (Ser, Thr), Green-Hydrophobic (Ala, Ile, Phe, Met, Pro), Light Purple-Basic (Lys), Gray- Water molecules, Darker gray-metal atom, Light YellowGlycine, Deep Purple- Unspecified molecules and the Grayish circles represent Solvent exposure. Interactions are shown as colored lines- Solid pink lines with arrow- H-bond in the target (backbone), Dotted pink lines with arrow- H-bond between receptor and ligand (side-chain), Solid pink lines without arrow- Metal co-ordination, Green line- Pi-Pi stacking interaction, Green dotted lines- Distances, Partially blue and red colored lines- Salt bridges. Ligands exposed to solvent are represented by grey sphere. The colored lines show the protein pocket for the ligand according to nearest atom. Interruptions of the lines indicate the opening of the pocket. In the 3D representations, the proteins are represented in Solid ribbon model and the ligands are represented in Stick model. 


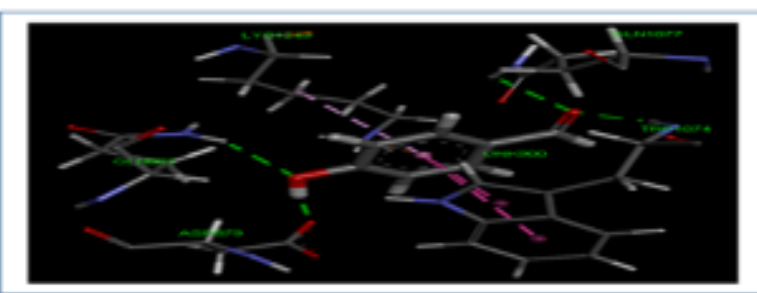

A
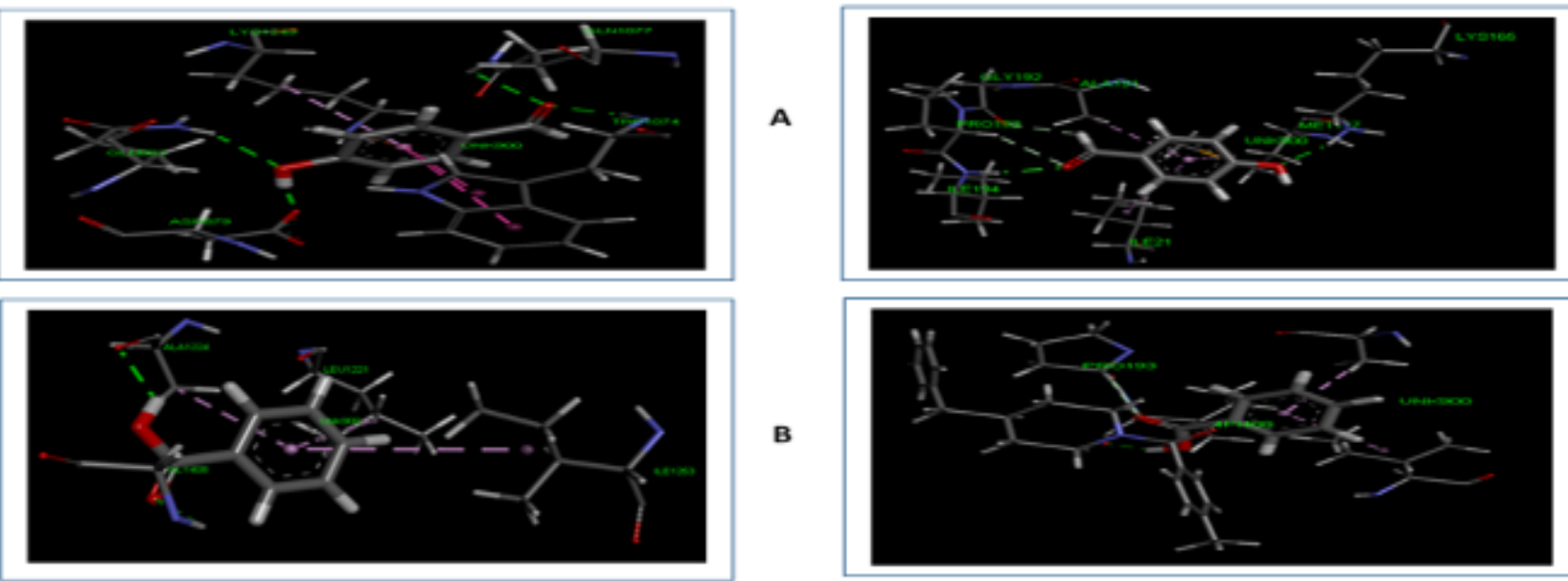

B
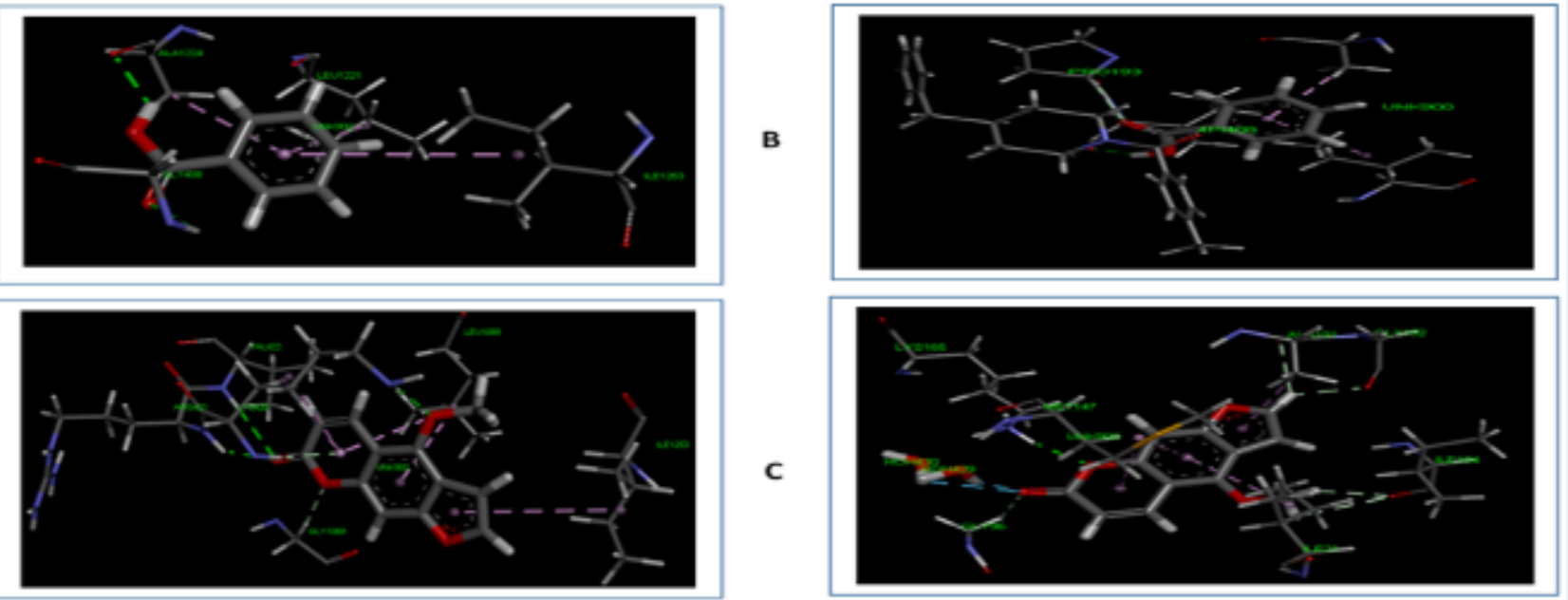

C
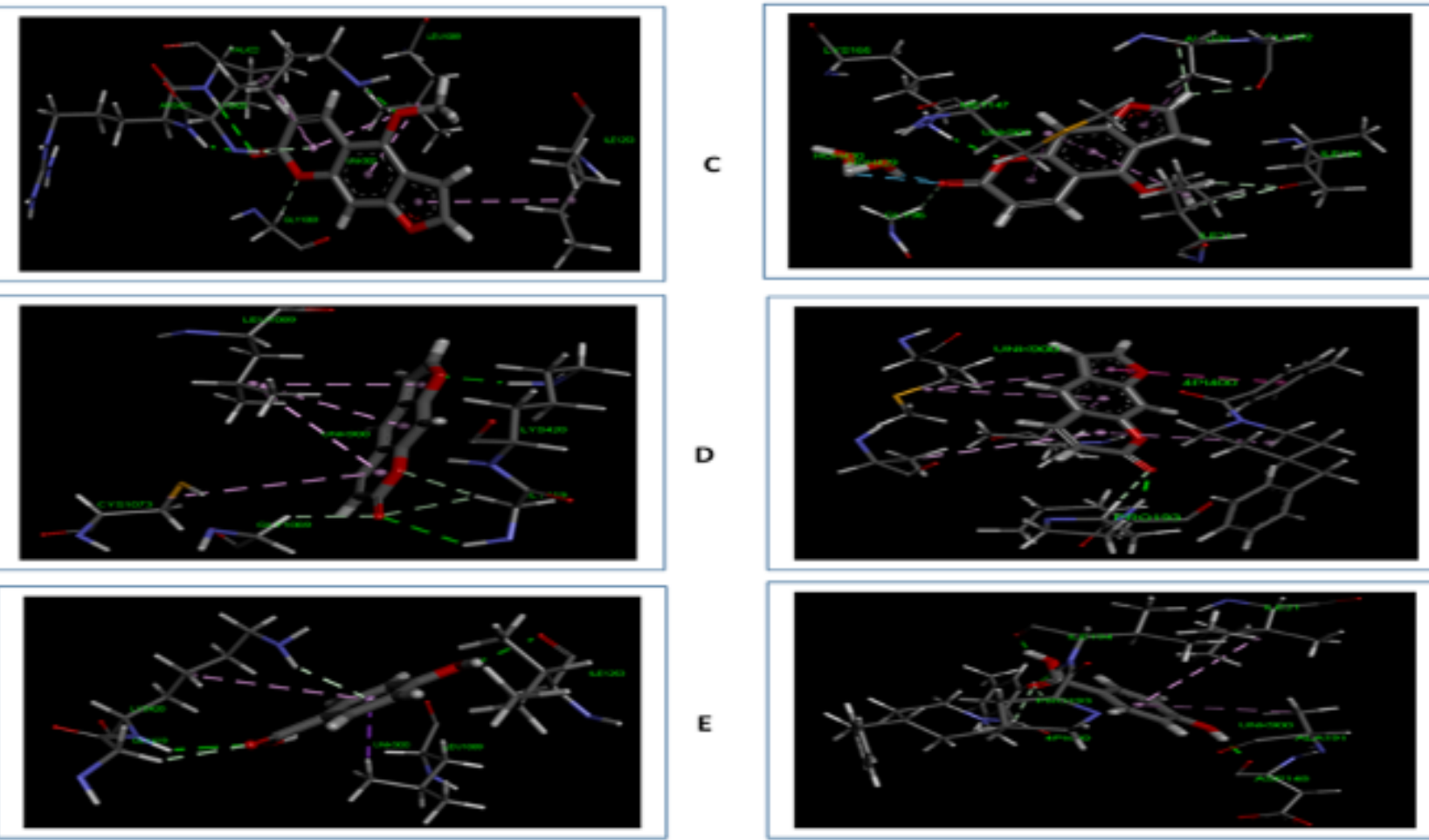

Interactions between the ligands and RNA polymerase

Interactions between the ligands and InhA protein 
Figure 05. Figure showing the various types of bonds and amino acids that take part in the interaction between the selected ligands and MTB RNA polymerase (left) and InhA protein (right). Interacting amino acid residues of target molecules are labeled in the diagram and dotted lines depict interaction between ligand and receptor. Green dotted lines- Conventional bond, Light pinkAlkyl/Pi-Alkyl interactions, Yellow- Pi-Sulfur/Sulphur-X interaction, Deep pink- Pi-Pi stacked bond, Orange- Charge-Charge interaction, Purple- Pi-Sigma interaction, Red- Donor-Donor interaction. Here, A. 4-hydroxybenzaldehyde, B. benzoic acid, C. bergapten, D. psoralen, E. phydroxybenzoic acid.

\subsection{Druglikeness Properties}

All the ligands obeyed the Lipinski's rule of five: molecular weight (acceptable range: $\leq 500)$, total number of hydrogen bond donors (acceptable range: $\leq 5$ ), total number of hydrogen bond acceptors (acceptable range: $\leq 10)$, lipophilicity (LogP, acceptable range: $\leq 5)$ and molar refractivity $(40-130)$

(Lipinski, 2004). Bergapten had the highest molecular weight of $216.19 \mathrm{~g} / \mathrm{mol}$. 4hydroxybenzaldehyde and benzoic acid showed similar molecular weight of $122.12 \mathrm{~g} / \mathrm{mol}$, which was the lowest among all the ligands. The highest consensus Log $P_{\mathrm{o}} / \mathrm{w}$ value was shown by bergapten (2.16) and the lowest value was generated by p-hydroxybenzoic acid of 1.05. However, bergapten showed the lowest $\log S$ value of -2.93 and 4-hydroxybenzaldehyde showed the LogS value of -1.87. Both 4-hydroxybenzaldehyde and benzoic acid had 2 hydrogen bond acceptors each and 1 hydrogen bond donors each. Bargapten had 4 hydrogen bond acceptors and psoralen had 3 hydrogen bond acceptors, however, both of them didn't have any hydrogen bond donors. Phydroxybenzoic acid had 3 hydrogen bond acceptors and 2 hydrogen bond donors. Phydroxybenzoic acid possessed the largest topological polar surface area (TPSA) of $57.53 \AA^{2}$. 
However, both 4-hydroxybenzaldehyde and benzoic acid showed similar TPSA value of $37.30 \AA^{2}$, which was the lowest TPSA value. Benzoic acid had the highest drug-likeness score of -1.4 and 4-hydroxybenzaldehyde had the lowest score of -6.31. P-hydroxybenzoic acid generated the highest drug score of 0.35 and bergapten generated lowest drug score of 0.10 . However, only bergapten was found to be reproductive effective and tumorigenic. And only 4hydroxybenzaldehyde and benzoic acid were irritant and all the ligands were found to be mutagenic. The values of the drug-likeness properties are listed in Table $\mathbf{0 4}$. 


\begin{tabular}{|c|c|c|c|c|c|}
\hline $\begin{array}{c}\text { Druglikeness } \\
\text { properties }\end{array}$ & 4-hydroxybenzaldehyde & Benzoic acid & Bergapten & Psoralen & p-hydroxybenzoic acid \\
\hline $\begin{array}{c}\text { Lipinski's rule of } \\
\text { five }\end{array}$ & Yes & Yes & Yes & Yes & Yes \\
\hline $\begin{array}{l}\text { Molecular weight } \\
\qquad(\mathrm{g} / \mathrm{mol})\end{array}$ & 122.12 & 122.12 & 216.19 & 186.16 & 138.12 \\
\hline $\begin{array}{c}\text { Concensus Log } \\
P_{\mathrm{o} / \mathrm{w}}\end{array}$ & 1.17 & 1.44 & 2.16 & 2.12 & 1.05 \\
\hline $\log S$ & -1.87 & -2.20 & -2.93 & -2.73 & -2.07 \\
\hline $\begin{array}{l}\text { Num. H-bond } \\
\text { acceptors }\end{array}$ & 2 & 2 & 4 & 3 & 3 \\
\hline $\begin{array}{c}\text { Num. H-bond } \\
\text { donors }\end{array}$ & 1 & 1 & 0 & 0 & 2 \\
\hline $\begin{array}{c}\text { Molar } \\
\text { Refractivity }\end{array}$ & 33.85 & 33.40 & 58.75 & 52.26 & 35.42 \\
\hline Ghose & No (3 violations) & $\begin{array}{c}\text { No (3 } \\
\text { violations) }\end{array}$ & Yes & Yes & No (3 violations) \\
\hline Veber & Yes & Yes & Yes & Yes & Yes \\
\hline Egan & Yes & Yes & Yes & Yes & Yes \\
\hline Muegge & No (1 violation) & $\begin{array}{c}\text { No (1 } \\
\text { violation) }\end{array}$ & Yes & No (1 violation) & No (1 violation) \\
\hline TPSA $\left(\AA^{2}\right)$ & 37.30 & 37.30 & 52.58 & 43.35 & 57.53 \\
\hline $\begin{array}{c}\text { Druglikeness } \\
\text { score }\end{array}$ & -6.3 & -1.4 & -3.3 & -3.2 & -1.5 \\
\hline Drug score & 0.17 & 0.21 & 0.10 & 0.27 & 0.35 \\
\hline
\end{tabular}




\begin{tabular}{|c|c|c|c|c|c|}
\hline $\begin{array}{c}\text { Reproductive } \\
\text { effective }\end{array}$ & No & No & Yes (High & No \\
risk) & No & No & No \\
\hline Irritant & Yes (High risk) & Yes (High risk) & No & No \\
\hline Tumorigenic & No & No & Yes (High & Yes (High risk) \\
\hline Mutagenic & Yes (High risk) & Yes (High risk) & Yes (High & Yes (High risk) & risk) \\
\hline
\end{tabular}

Table 04. Results of the druglikeness property studies of the selected ligand molecules.

\subsection{ADME/T Test}

The results of the ADME/T test are listed in Table 05. In the absorption section, all the selected ligands showed Caco-2 permeability and human intestinal absorption capability. However, all of them were not $\mathrm{p}$-gp inhibitor as well as p-gp substrate. In the distribution section, all of the ligands showed blood-brain barrier permeability. However, p-hydroxybenzoic acid and 4hydroxybenzaldehyde showed relatively low plasma protein binding capability than the other three ligands. In the metabolism section, 4-hydroxybenzaldehyde, benzoic acid and p-hydroxybenzoic acid were non-inhibitors as well as non-substrate for all the CYP450 isoenzymes. However, due to the unavailability of data in the server, the CYP450 1A2 and CYP450 2C19 substrates were not determined. However, bergapten and psoralen showed quite similar results in the metabolism section with inhibitory effects on the CYP450 1A2, 3A4, 2C9, 2 D6 and 2C19. In the excretion section, 4-hydroxybenzaldehyde had the highest half-life of $1.7 \mathrm{~h}$. In the toxicity section, none of 
the molecules was hERG blocker and only bergapten was found to be human hepatotoxic as well as Ames positive. However, bergapten and psoralen showed drug-induced liver injury capability.

Table 05. Results of the ADME/T studies of the selected ligand molecules. The ADME/T tests were carried out by online servers, admetSAR (http://lmmd.ecust.edu.cn/admetsar2) as well as the ADMETlab (http://admet.scbdd.com/). 


\begin{tabular}{|c|c|c|c|c|c|c|}
\hline Class & Properties & $\begin{array}{c}\text { 4- } \\
\text { hydroxybenzaldeh } \\
\text { yde (with } \\
\text { probability) }\end{array}$ & $\begin{array}{c}\text { Benzoic acid (with } \\
\text { probability) }\end{array}$ & $\begin{array}{c}\text { Bergapten (with } \\
\text { probability) }\end{array}$ & $\begin{array}{c}\text { Psoralen (with } \\
\text { probability) }\end{array}$ & $\begin{array}{c}\text { P- } \\
\text { hydroxybenzoic } \\
\text { acid }\end{array}$ \\
\hline \multirow[t]{4}{*}{ Absorption } & Caco- 2 permeability & Positive (0.965) & Positive (0.953) & Positive (0.819) & Positive (0.863) & Positive (0.923) \\
\hline & Pgp-inhibitor & Negative (0.987) & Negative (0.989) & Negative (0.878) & Negative (0.934) & Negative (0.986) \\
\hline & Pgp-substrate & Negative (0.989) & Negative (0.997) & Negative (0.924) & Negative (0.951) & Negative (0.990) \\
\hline & $\begin{array}{c}\text { HIA (Human } \\
\text { Intestinal Absorption) }\end{array}$ & Positive (0.990) & Positive (0.981) & Positive (0.991) & Positive (0.988) & Positive (0.983) \\
\hline \multirow[t]{2}{*}{ Distribution } & $\begin{array}{c}\text { PPB (Plasma Protein } \\
\text { Binding) }\end{array}$ & Good, $48.4 \%$ & High, $77.7 \%$ & High, $79.5 \%$ & High, $85.3 \%$ & Good, $55.6 \%$ \\
\hline & $\begin{array}{c}\text { BBB (Blood-Brain } \\
\text { Barrier) }\end{array}$ & Positive (0.848) & Positive (0.781) & Positive $(0.883)$ & Positive (0.852) & Negative $(0.7620$ \\
\hline \multirow[t]{7}{*}{ Metabolism } & $\begin{array}{l}\text { CYP450 1A2 } \\
\text { inhibition }\end{array}$ & Negative (0.752) & Negative $(0.853)$ & Positive (0.974) & Positive (0.910) & Negative (0.975) \\
\hline & $\begin{array}{l}\text { CYP450 1A2 } \\
\text { substrate }\end{array}$ & - & - & - & - & - \\
\hline & $\begin{array}{l}\text { CYP450 3A4 } \\
\text { inhibition }\end{array}$ & Negative (0.915) & Negative (0.982) & Positive (0.795) & Positive (0.767) & Negative (0.949) \\
\hline & $\begin{array}{l}\text { CYP450 3A4 } \\
\text { substrate }\end{array}$ & Negative $(0.795)$ & Negative (0.879) & Negative (0.607) & Negative (0.753) & Negative $(0.826)$ \\
\hline & $\begin{array}{l}\text { CYP450 2C9 } \\
\text { inhibition }\end{array}$ & Negative $(0.985)$ & Negative (0.986) & Positive (0.825) & Positive (0.534) & Negative (0.969) \\
\hline & $\begin{array}{c}\text { CYP450 2C9 } \\
\text { substrate }\end{array}$ & Negative (0.619) & Negative (0.806) & Negative (1.000) & Negative (1.000) & Negative $(0.815)$ \\
\hline & $\begin{array}{l}\text { CYP450 2C19 } \\
\text { inhibition }\end{array}$ & Negative (0.905) & Negative (0.987) & Positive (0.929) & Positive (0.795) & Negative $(0.965)$ \\
\hline
\end{tabular}




\begin{tabular}{|c|c|c|c|c|c|c|}
\hline & $\begin{array}{l}\text { CYP450 2C19 } \\
\text { substrate }\end{array}$ & - & - & - & - & - \\
\hline & $\begin{array}{c}\text { CYP450 2D6 } \\
\text { inhibition }\end{array}$ & Negative $(0.970)$ & Negative (0.957) & Positive (0.893) & Positive (0.676) & Negative (0.982) \\
\hline & $\begin{array}{c}\text { CYP450 2D6 } \\
\text { substrate }\end{array}$ & Negative (0.729) & Negative $(0.885)$ & Negative (0.815) & Negative (0.844) & Negative $(0.873)$ \\
\hline & $\begin{array}{l}\text { Subcellular } \\
\text { localization }\end{array}$ & Mitochondria & Mitochondria & Mitochondria & Mitochondria & Mitochondria \\
\hline Excretion & $\mathrm{T}_{1 / 2}(\mathrm{~h})$ & 1.7 & 1.5 & 0.2 & 1.423 & 0.773 \\
\hline \multirow[t]{4}{*}{ Toxicity } & $\begin{array}{c}\text { hERG (hERG } \\
\text { Blockers) }\end{array}$ & Non-blocker (0.198) & Non-blocker (0.169) & $\begin{array}{c}\text { Non-blocker } \\
(0.344)\end{array}$ & $\begin{array}{c}\text { Non-blocker } \\
(0.298)\end{array}$ & $\begin{array}{c}\text { Non-blocker } \\
(0.238)\end{array}$ \\
\hline & $\begin{array}{l}\text { H-HT (Human } \\
\text { Hepatotoxicity) }\end{array}$ & Negative (0.132) & Negative (0.102) & Positive (0.826) & Negative (0.082) & Negative (0.064) \\
\hline & $\begin{array}{l}\text { Ames (Ames } \\
\text { Mutagenicity) }\end{array}$ & Negative (0.006) & Negative (0.078) & Positive (0.882) & Negative (0.072) & Negative $(0.068)$ \\
\hline & $\begin{array}{c}\text { DILI (Drug Induced } \\
\text { Liver Injury) }\end{array}$ & Negative (0.848) & Negative $(0.402)$ & Positive (0.952) & Positive (0.924) & Negative (0.206) \\
\hline
\end{tabular}




\subsection{P450 Site of Metabolism (SOM) Prediction}

The P450 SOM prediction was carried out for the five selected ligand molecules and the SOM prediction was performed for CYPs 1A2, 2A6, 2B6, 2C19, 2C8, 2C9, 2D6, 2E1 and 3A4. 4hydroxybenzoic acid showed 6 SOMs for all the CYP450 isoenzymes, and both bergapten and psoralen showed 3 SOMs each, for all the CYP450 isoenzymes. However, benzoic acid showed 6 SOMs for CYP450 1A2 and CYP450 2C8, 4 SOMs for CYP450 2A6 and 5 SOMs for rest of the CYP450 isoenzymes. P-hydroxybenzoic acid showed 5 SOMs for CYP450 2A6, 6 SOMs for CYP450 2E1 and CYP450 3A4 and 7 SOMs for the rest of the CYP450 isoenzymes. The results of P450 SOM are listed in Table 06.

Table 06. The result of P450 site of metabolism prediction of the selected ligand molecules.

\begin{tabular}{|c|c|c|c|c|c|}
\hline $\begin{array}{l}\text { Names of } \\
\text { P450 } \\
\text { isoenzymes }\end{array}$ & $\begin{array}{l}\text { 4- } \\
\text { hydroxybenzal } \\
\text { dehyde }\end{array}$ & Benzoic acid & Bergapten & Psoralen & $\begin{array}{l}\text { P- } \\
\text { hydroxybenzoic } \\
\text { acid }\end{array}$ \\
\hline 1A2 & (1) & & & & \\
\hline 2A6 & & & & & \\
\hline
\end{tabular}




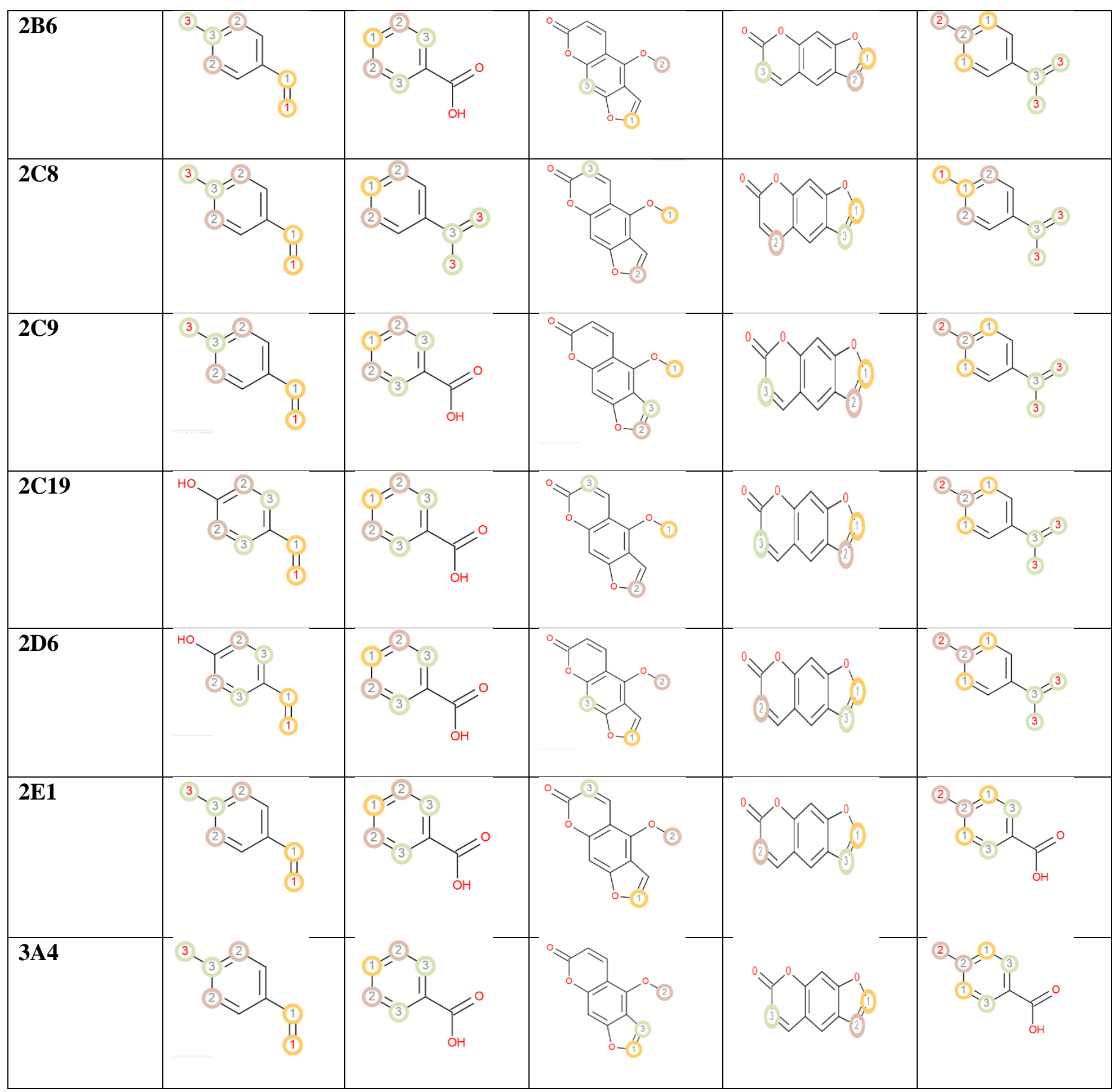




\subsection{Pharmacophore Modelling}

In the pharmacophore modelling experiment, all the ligands generated pharmacophore hypotheses while inhibiting both MTB RNA polymerase and InhA protein. 4-hydroxybenzaldehyde generated 4 point hypothesis (features: A1, A2, D3, R4) with MTB RNA polymerase and formed 1 hydrogen bond, 1 pi-cation bond, 3 bad bonds and 1 ugly bond with the binding pocket of the protein. It generated 1 point hypothesis with the InhA protein (feature: A1) and formed 1 pi-pi interaction. Benzoic acid formed 4 point hypothesis (features: A1, A2, D3, R4) while inhibiting the MTB RNA polymerase and formed 1 hydrogen bond and 1 pi-pi interaction within the binding pocket of the receptor. Benzoic acid formed 2 point hypothesis (features: A2, D3) and formed 5 hydrogen bonds and 1 pi-pi interaction within the binding pocket of the receptor protein, InhA protein. Bergapten generated 6 point hypothesis (features: A1, A2, A4, H5, R7, R8) with MTB RNA polymerase and formed 2 bad bonds. However, it generated 3 point hypothesis (features: A2, H5, R7) with the InhA protein and formed 7 hydrogen bonds, 1 pi-pi interaction and 3 bad bonds within the binding pocket of the receptor. Psoralen generated 4 point hypothesis (A1, A2, R4, R6) with MTB RNA polymerase, however, it didn't form any bond with the protein. On the other hand, it generated 3 point hypothesis (features: A1, R4, R6) with InhA protein and formed 1 pi-pi interaction, 1 ugly bond and 3 bad bonds. P-hydroxybenzoic acid generated 4 point hypothesis (A1, A2, D4, R6) with MTB RNA polymerase and formed 2 hydrogen bonds and 3 bad bonds. Moreover, it generated 3 point hypothesis (features: A2, D4, D5) with the InhA protein and formed 1 pi-pi interaction and 3 bad bonds within the binding pocket of the receptor. However, all the ligands also showed a significant number of good bonds with their receptor proteins (Figure 06 and Figure 07). 


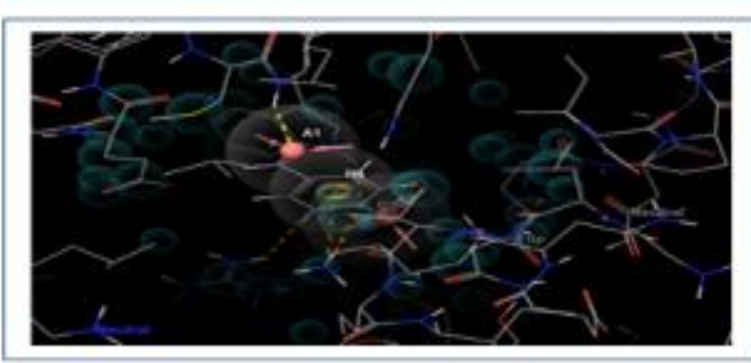

A
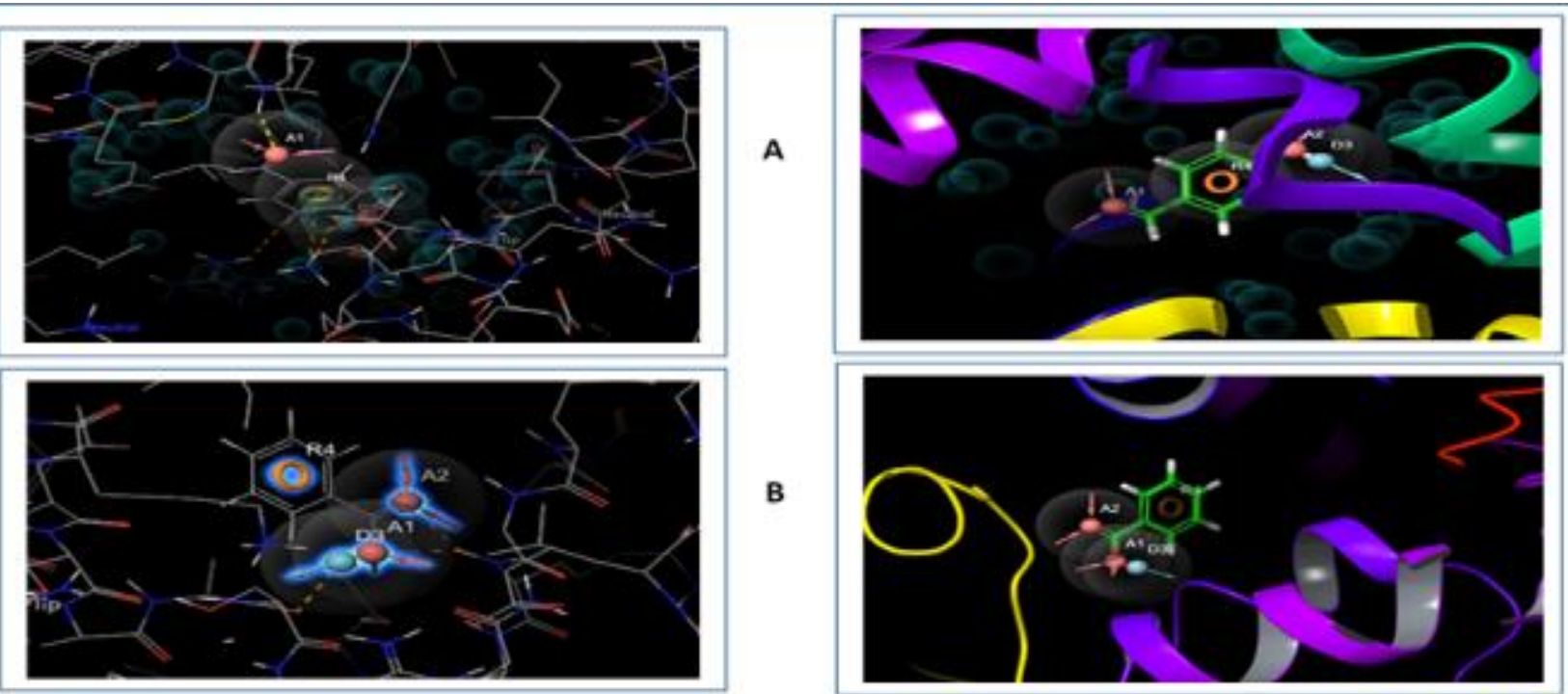

B
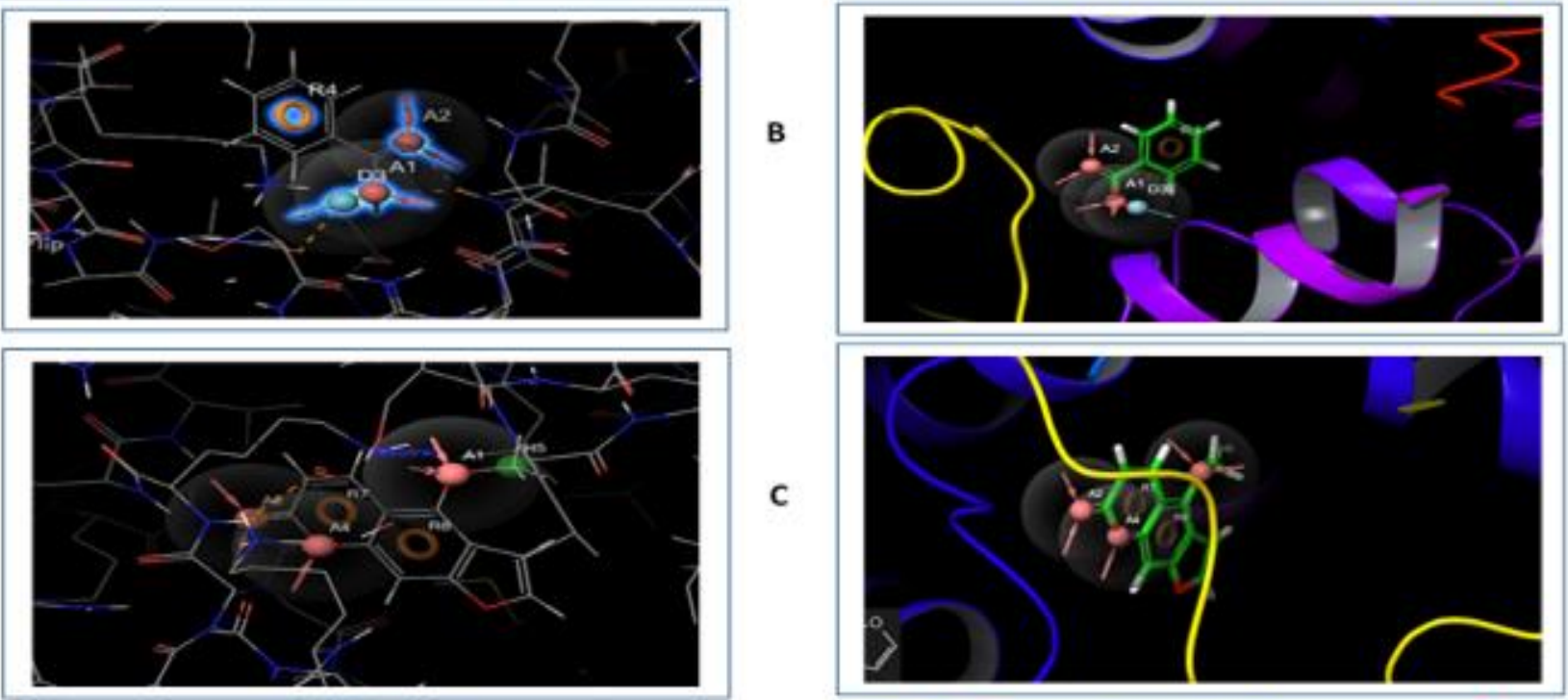

c
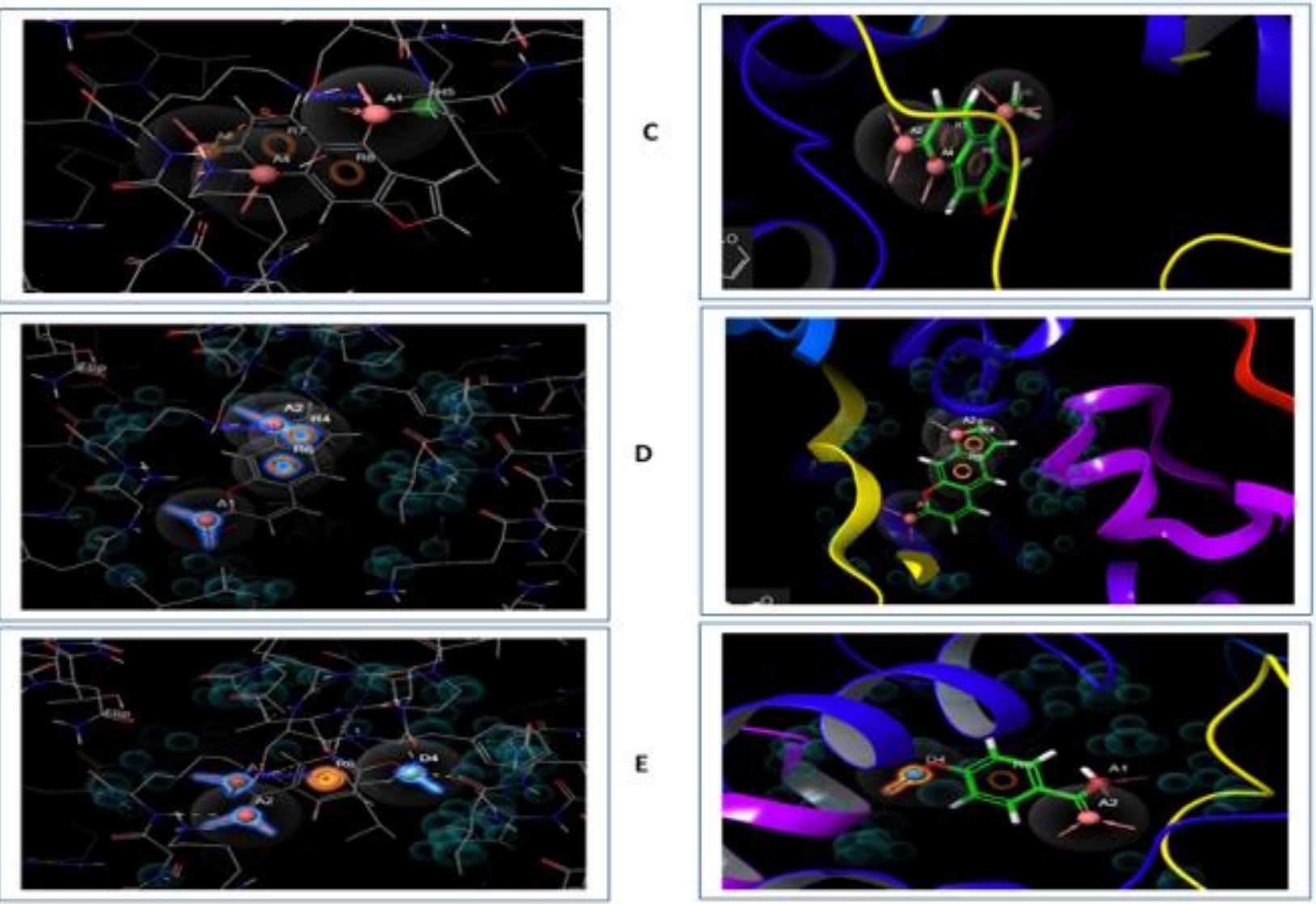

Figure 06. Figure showing the 2D (left) and 3D (right) representations of the pharmacophore hypotheses generated by the ligands while inhibiting the MTB RNA polymerase. Here, A. 4-hydroxybenzaldehyde, B. benzoic acid, C. bergapten, D. psoralen, E. p-hydroxybenzoic acid. The interactions between the ligand and the receptor in the hypothesis were presented by dotted dashed lines, yellow colour- hydrogen bonds and green colour- pi-cation interaction. The bad contacts between the ligands and the pharmacophore are respresented. The pharmacophore modelling was carried out by Maestro-Schrödinger Suite 2018-4. 


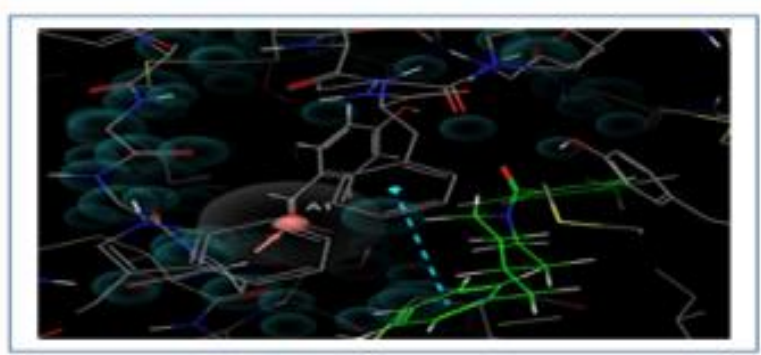

A
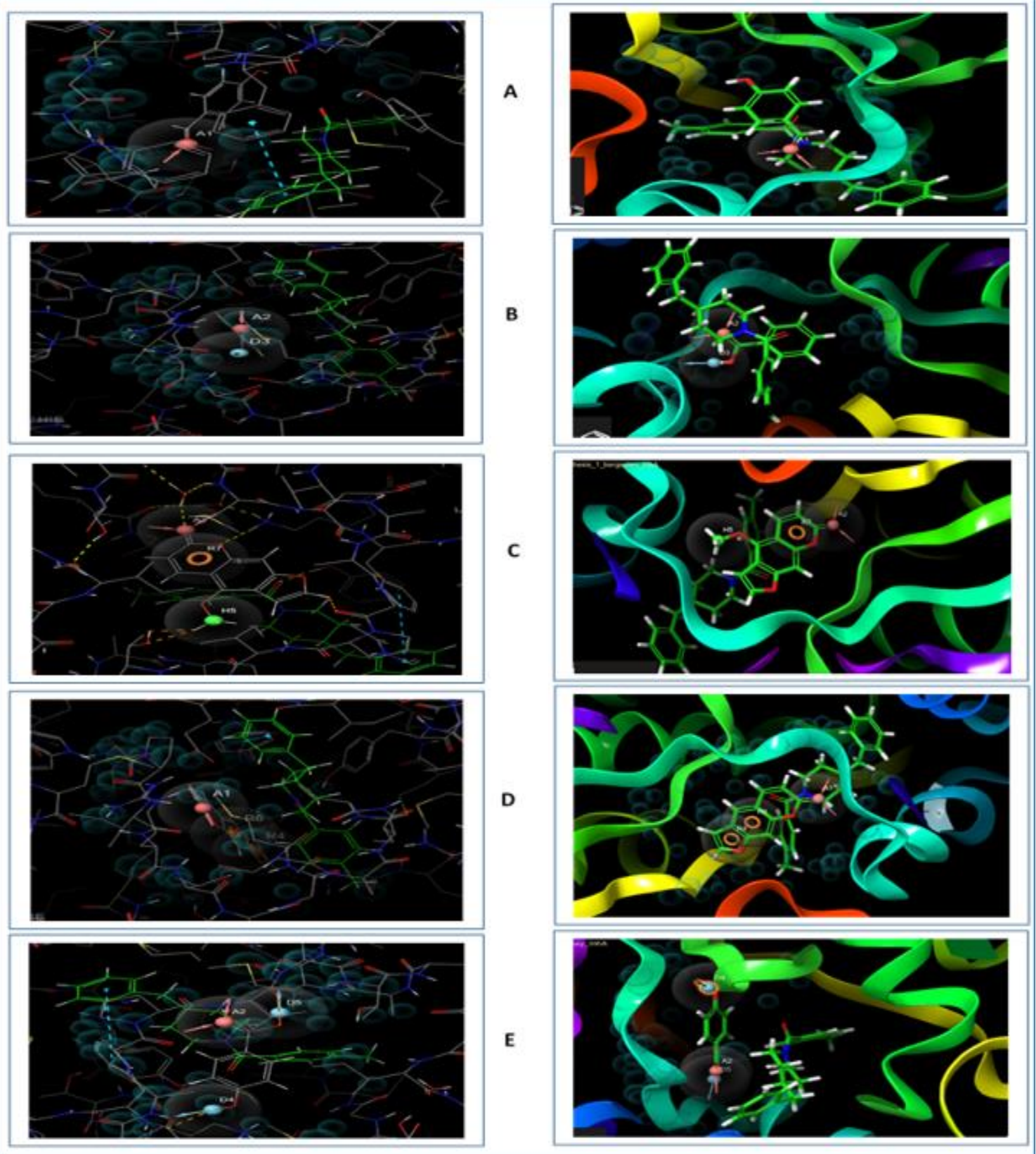

Figure 07. Figure showing the 2D (left) and 3D (right) representations of the pharmacophore hypotheses generated by the ligands while inhibiting the InhA protein. Here, A. 4-hydroxybenzaldehyde, B. benzoic acid, C. bergapten, D. psoralen, E. p-hydroxybenzoic acid. The interactions between the ligand and the receptor in the hypothesis were presented by dotted dashed lines, yellow colour- hydrogen bonds and green colour- pi-cation interaction. The bad contacts between the ligands and the pharmacophore are respresented. The pharmacophore modelling was carried out by Maestro-Schrödinger Suite 2018-4. 


\subsection{Solubility Prediction}

The results of the solubility test of all the ligands are listed in Table $\mathbf{0 8}$. Bergapten showed the highest QPlogPC16 score of 4.392 and 4-hydroxybenzaldehyde showed the lowest QPlogPC16 score of 2.298. Bergaptan also generated the highest QPlogPoct score of 9.129 and the second highest QPlogPoct score was showed by p-hydroxybenzoic acid. However, both benzoic acid and psoralen showed almost similar QPlogPoct results of 4.474 and 4.881, respectively. Bergapten and p-hydroxybenzoic acid also generated the highest and second-highest QPlogPw scores of 8.804 and 6.296, respectively. However, 4-hydroxybenzaldehyde showed the highest QPlogPo/w value of 0.071 and p-hydroxybenzoic acid generated the highest QPlogS score of 0.948. Benzoic acid showed the highest score of CIQPlogS (-0.284) and bergapten generated the lowest CIQPlogS score of -0.883 .

Table 08. List of the solubility tests of the selected ligands. The tests were carried out by QikPrep wizard of Maestro-Schrödinger Suite 2018-4. Here,

aPredicted hexadecane/gas partition coefficient (Acceptable range: 4.0 - 18.0); bPredicted octanol/gas partition coefficient (Acceptable range: 8.0 - 35.0); CPredicted water/gas partition coefficient (Acceptable range: 4.0 - 45.0); dPredicted octanol/water partition coefficient (Acceptable range: $-2.0-6.5$ ); ePredicted aqueous solubility, $\mathrm{S}$ in mol dm-3 (Acceptable range: $-6.5-0.5$ ) f fonformation-independent predicted aqueous solubility, $\mathrm{S}$ in mol dm-3(Acceptable range: $-6.5-0.5)$. 


\begin{tabular}{|l|l|l|l|l|l|l|}
\hline Compound Name & QPlogPC16 $^{\mathbf{a}}$ & QPlogPoct $^{\mathbf{b}}$ & QPlogPw $^{\mathbf{c}}$ & QPlogPo/w $^{\mathbf{d}}$ & QPlogS $^{\mathrm{e}}$ & $\mathbf{C I Q P l o g S}^{\mathbf{f}}$ \\
\hline $\begin{array}{l}\text { hydroxybenzaldehy } \\
\text { de }\end{array}$ & 2.298 & 3.081 & 2.406 & 0.071 & 0.241 & -0.401 \\
\hline Benzoic acid & 2.536 & & & & & \\
\hline Bergapten & 4.392 & 4.474 & 4.803 & -0.193 & 0.097 & -0.284 \\
\hline Psoralen & 2.989 & 9.129 & 8.804 & -0.291 & -0.714 & -0.883 \\
\hline $\begin{array}{l}\text { P-hydroxybenzoic } \\
\text { acid }\end{array}$ & 3.580 & 4.881 & 4.697 & -0.358 & 0.075 & -0.631 \\
\hline
\end{tabular}

\subsection{DFT Calculations}

Table 09 lists the detailed energy of HOMO, LUMO, Gap, hardness, and softness of the compounds. All the molecules successfully generated the HOMO-LUMO structures. The highest HOMO score or energy was showed by bergapten of $-0.112 \mathrm{eV}$ and the lowest was generated by p-hydroxybenzoic acid of $-0.198 \mathrm{eV}$. Psoralen generated quite similar score of p-hydroxybenzoic acid of -0.197 eV. 4-hydroxybenzaldehyde and benzoic acid showed similar scores of $-0.174 \mathrm{eV}$. Psoralen generated the lowest LUMO score of $0.039 \mathrm{eV}$ and p-hydroxybenzoic acid generated the highest LUMO score of $0.100 \mathrm{eV}$. However, p-hydroxybenzoic acid showed the highest gap score of $0.298 \mathrm{eV}$ and bergapten generated the lowest gap score of $0.164 \mathrm{eV}$. The molecules showed gap scores of quite similar results. 4-hydroxybenzaldehyde, benzoic acid and psoralen showed quite similar hardness scores of $0.114,0.115$ and $0.118 \mathrm{eV}$ respectively. P-hydroxybenzoic acid gave the highest hardness score of $0.149 \mathrm{eV}$ and bergaten showed the lowest hardness score of 0.082 $\mathrm{eV}$. For this reason, bergapten generated the highest softness score of 12.190 and phydroxybenzoic acid generated the lowest softness score of 6.710. Moreover, bergapten generated 
the highest dipole moment score of 7.186 debye and benzoic acid generated the lowest dipole moment score of 2.217 debye. The HOMO-LUMO representations of the ligands are shown in Figure 08.

Table 09. The results of the DFT calculations of the selected ligands.

\begin{tabular}{|c|c|c|c|c|c|c|}
\hline Name of the ligands & $\begin{array}{l}\text { HOMO (in } \\
\mathrm{eV})\end{array}$ & $\begin{array}{l}\text { LUMO (in } \\
\mathrm{eV})\end{array}$ & Gap (in eV) & $\begin{array}{l}\text { Hardness (in } \\
\text { eV) }\end{array}$ & $\begin{array}{l}\text { Softness (in } \\
\mathrm{eV} \text { ) }\end{array}$ & $\begin{array}{l}\text { Dipole moment } \\
\text { (in Debye) }\end{array}$ \\
\hline 4-hydroxybenzaldehyde & -0.174 & 0.053 & 0.227 & 0.114 & 8.770 & 4.839 \\
\hline Benzoic acid & -0.174 & 0.055 & 0.229 & 0.115 & 8.690 & 2.217 \\
\hline Bergapten & -0.112 & 0.052 & 0.164 & 0.082 & 12.190 & 7.186 \\
\hline Psoralen & -0.197 & 0.039 & 0.236 & 0.118 & 8.470 & 5.272 \\
\hline P-hydroxybenzoic acid & -0.198 & 0.100 & 0.298 & 0.149 & 6.710 & 2.524 \\
\hline
\end{tabular}




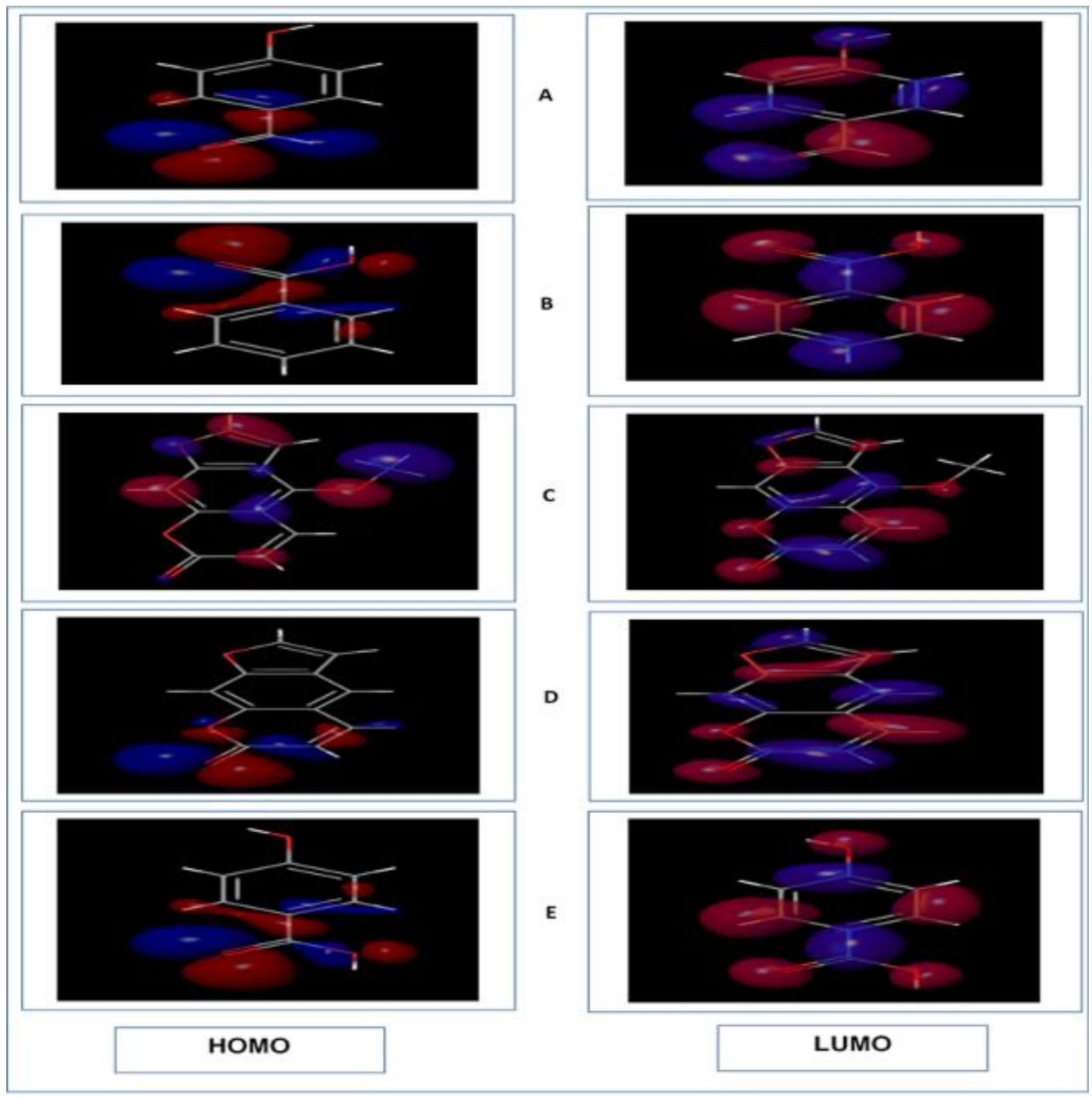

Figure 08. The HOMO (left) and LUMO (right) structures of the selected ligands generated by the Jaguar wizard of Maestro-Schrödinger Suite 2018-4. A. 4-hydroxybenzaldehyde, B. benzoic acid, C. bergapten, D. psoralen, E. p-hydroxybenzoic acid. 


\subsection{PASS (Prediction of Activity Spectra for Substances) Prediction Study}

In the PASS prediction study, the predicted LD50 value and toxicity class of 4hydroxybenzaldehyde were not determined due to the unavailability of data in the server ProTox II. However, bergapten had the predicted LD50 value of $8100 \mathrm{mg} / \mathrm{kg}$ and toxicity class of 6 . However, the PASS prediction study was conducted for 10 intended biological activities and 5 toxic effects. To carry out the PASS prediction experiment, $\mathrm{Pa}>0.7$ was kept since this threshold give highly reliable prediction (Geronikaki et al., 1999). Both 4-hydroxybenzaldehyde and bergapten showed activities: aldehyde oxidase inhibitor, CYP2A6 substrate, CYP2A substrate, CYP2E1 substrate and CYP1A2 substrate. However, 4-hydroxybenzaldehyde also showed nitrilase inhibitory activity, thioredoxin inhibitory activity and chymosin activity and bergapten also showed activities: HIF1A expression inhibitor and CYP2A11 substrate. The toxic effects showed by 4-hydroxybenzaldehyde were: weakness, vascular toxicity and fatty liver and bergapten showed the toxic effects: hypothermic and carcinogenic group 3. The results of PASS prediction studies are listed in Table 10 and Table 11. 
Table 10. The results of the biological activities PASS prediction study of the selected ligands. The prediction was conducted by using PASS-Way2Drug server (http://www.pharmaexpert.ru/passonline/).

\begin{tabular}{|c|c|c|c|c|c|}
\hline \multirow[t]{4}{*}{ SI no } & \multirow[t]{4}{*}{ Biological activities } & \multicolumn{2}{|c|}{$\begin{array}{l}\text { 4-hydroxbenzaldehyde } \\
\text { Predicted LD50: NA }\end{array}$} & \multicolumn{2}{|c|}{ Bergapten } \\
\hline & & Predic & NA & Predic & $0: 8100$ \\
\hline & & \multicolumn{2}{|c|}{ Toxicity class: NA } & \multicolumn{2}{|c|}{ Toxicity class: 6} \\
\hline & & $\mathbf{P a}$ & $\mathbf{P i}$ & $\mathbf{P a}$ & $\mathbf{P i}$ \\
\hline 01 & Aldehyde oxidase inhibitor & 0.951 & 0.003 & 0.747 & 0.013 \\
\hline 02 & CYP2A6 substrate & 0.854 & 0.004 & 0.921 & 0.003 \\
\hline 03 & CYP2A substrate & 0.854 & 0.004 & 0.922 & 0.004 \\
\hline 04 & CYP2E1 substrate & 0.0843 & 0.004 & 0.757 & 0.004 \\
\hline 05 & CYP1A2 substrate & 0.724 & 0.008 & 0.750 & 0.004 \\
\hline 06 & Nitrilase inhibitor & 0.883 & 0.002 & - & - \\
\hline 07 & HIF1A expression inhibitor & - & - & 0.732 & 0.017 \\
\hline 08 & CYP2A11 substrate & - & - & 0.923 & 0.001 \\
\hline 09 & Thioredoxin inhibitor & 0.757 & 0.005 & - & - \\
\hline 10 & Chymosin inhibitor & 0.760 & 0.029 & - & - \\
\hline
\end{tabular}


Table 11. The results of the adverse and toxic effects PASS prediction study of the selected ligands. The prediction was conducted by using PASS-Way2Drug server (http://www.pharmaexpert.ru/passonline/).

\begin{tabular}{|c|c|c|c|c|}
\hline Predicted adverse and toxic effects & \multicolumn{2}{|c|}{ 4-hydroxbenzaldehyde } & \multicolumn{2}{c|}{ Bergapten } \\
\cline { 2 - 5 } & Pa & Pi & Pa & Pi \\
\hline \hline Weakness & 0.862 & 0.011 & - & - \\
\hline Toxic, vascular & 0.813 & 0.015 & 0.743 & 0.004 \\
\hline Fatty liver & 0.866 & 0.003 & - & - \\
\hline Hypothermic & - & - & 0.730 & 0.012 \\
\hline Carcinogenic, group 3 & 0.710 & 0.021 & 0.703 & 0.006 \\
\hline
\end{tabular}

\section{Discussions}

Molecular docking generates a score based on the binding of ligand and receptor. The higher binding energy represents the lower bonding affinity and vice versa (Sarkar et al., 2019; Sarkar et al., 2020a). Studies have proved that the lowest glide energy corresponds to the best result (Raj and Varadwaj, 2016). The controls, rifampicin and isoniazid successfully docked with their target receptors. The control gave docking scores of $-4.813 \mathrm{Kcal} / \mathrm{mol}$ and $-6.018 \mathrm{Kcal} / \mathrm{mol}$, respectively and glide energies of $-25.247 \mathrm{Kcal} / \mathrm{mol}$ and $-29.728 \mathrm{Kcal} / \mathrm{mol}$, respectively. They generated quite good scores in the docking study.

4-hydroxybenzaldehyde showed the lowest binding energy of $-6.062 \mathrm{Kcal} / \mathrm{mol}$ when docked against MTB RNA polymerase and bergapten gave the lowest score $-8.068 \mathrm{Kcal} / \mathrm{mol}$ when docked against InhA protein. However, 4-hydroxybenzaldehyde generated the glide energy of -21.269 $\mathrm{Kcal} / \mathrm{mol}$, which was not very good result, since the result was quite high when compared with the other ligands, while docking with MTB RNA polymerase. On the other hand, bergapten, generated 
the lowest glide energy of $-35.218 \mathrm{Kcal} / \mathrm{mol}$, which is the most acceptable score among the ligands when docked against the InhA protein. For this reason, 4-hydroxybenzaldehyde and bergapten should be the best molecules to inhibit their targets. This is further confirmed by the MM-GBSA study. In the MM-GBSA study, the $\triangle$ GBind score is taken and the lowest (most negative) $\Delta$ GBind Score is always appreciable (Zhang et al., 2017, Ullah et al., 2020a; Sarkar et al., 2020b). 4hydroxybenzaldehyde generated $\Delta$ GBind Score of $-53.070 \mathrm{Kcal} / \mathrm{mol}$, wich was the lowest score among all the ligands when docked against MTB RNA polymerase and bergapten generated $\Delta$ GBind score of $-57.590 \mathrm{Kcal} / \mathrm{mol}$ among the ligands when docked against InhA protein. 4hydroxybenzaldehyde generated 04 hydrogen bonds when docked against MTB RNA polymerase, which was the second number of most hydrogen bonds (bergapten was the first ligand with 05 hydrogen bonds). On the other hand, bergapten generated the highest number of hydrogen bonds (08) when docked against InhA protein. For this reason, in the molecular docking experiment, 4hydroxybenzaldehyde and bergapten were the best ligands to inhibit MTB RNA polymerase and InhA protein, respectively (Table $\mathbf{0 2}$ and Table $\mathbf{0 3}$ ).

Estimation of druglikeness properties aims to improve the drug discovery and development process. Molecular weight and topological polar surface area (TPSA) affect the permeability of the drug molecule through the biological barrier. Higher molecular weight and TPSA reduce the permeability and vice versa. $\log \mathrm{P}$ is expressed in the context of lipophilicity. It is described as the logarithm of partition coefficient of the candidate molecule in organic and aqueous phase. Lipophilicity influences the absorption of the drug molecule inside the body. Higher $\operatorname{LogP}$ represents lower absorption and vice versa (Ullah et al., 2019). LogS value influences the solubility of the candidate molecule and the lowest value is always preferred. Moreover, the more the number of hydrogen bonds, the greater the strength of interaction is and vice versa (Lipinski et al., 1997, 
Pollastri, 2010; Hubbard and Kamran Haider, 2001). Moreover, according to the Ghose filter, a candidate drug should have $\log \mathrm{P}$ value between -0.4 and 5.6, molecular weight between 160 and 480, molar refractivity between 40 and 130 and the total number of atoms between 20 and 70 , to qualify as a successful drug (Ghose et al., 1999). Veber rule describes that the oral bioavailability of a candidate drug depends on two factors: 10 or fewer numbers of rotatable bonds and the polar surface are which should be equal to or less than $140 \AA 2$ (Veber et al., 2002). Furthermore, according to the Egan rule, the absorption of a candidate drug molecule depends on two factors: the polar surface area (PSA) and AlogP98 (the logarithm of partition co-efficient between noctanol and water) (Egan et al., 2000). And according to the Muegge rule, for a drug like chemical compound to become a successful drug, it has to pass a pharmacophore point filter, which was developed by the scientists (Muegge et al., 2001). According to the druglikensess property experiment, p-hydroxybenzoic acid should be considered as the best molecule since it had quite low molecular weight $(138.12 \mathrm{~g} / \mathrm{mol})$, the lowest $\operatorname{LogP}$ value of 1.05 , the highest druglikeness score of -1.5 , the highest drug score of 0.35 and no reproductive effectiveness, irritant properties and tumorigenic effects. However, it was found to be a highly mutagenic agent and it had the highest TPSA score of $57.53 \AA^{2}$. Psoralen also showed good molecular weight of $186.16 \mathrm{~g} / \mathrm{mol}$ and relatively good LogS value, drug score of 0.27 , TPSA score of $43.35 \AA^{2}$ and no reproductive effectiveness, irritant properties and tumorigenic effects were found. However, it didn't perform well like p-hydroxybenzoic acid. Other ligand molecules also performed quite similarly in the druglikeness studies. However, all the ligands obeyed the Lipinski's rule of five. Only bergapten followed the Ghose, Veber, Egan and Muegge rules of druglikeness properties. 4hydroxybenzaldehyde. Benzoic acid and p-hydroxybenzoic acid violated Ghose and Muegge rules and psoralen violated the Muegge rule. 
$\mathrm{ADME} / \mathrm{T}$ tests evaluate the pharmacological and pharmacodynamic properties of a candidate drug molecule within biological system. Blood brain barrier is very important for those drugs that target primarily the brain cells. Since, the oral delivery system is the most commonly used route of drug administration, therefore, it is expected that the drug is highly absorbed in intestinal tissue. Pglycoprotein protein in the cell membrane facilitates the transport of many drugs. Therefore, its inhibition affects the drug transport. In vitro study of drug permeability test utilizes Caco-2 cell line and its permeability reflects that the drug is easily absorbed in the intestine. Orally absorbed drugs travel through the blood circulation and deposit back to liver. In the liver, they are metabolized by group of enzymes of cytochrome P450 family and excreted as bile or urine. Therefore, inhibition of any of the enzymes of this family might affect biodegradation of the drug molecule (Li, 2001; Guengerich, 1999; Sarkar et al., 2020d). The binding of drugs to the plasma proteins is an important pharmacological parameter which influences the pharmacodynamics of the drugs and their circulation and excretion. A drug's proficiency depends on the degree of its binding with the plasma protein. A drug can diffuse easily through the cell membrane if it binds to the plasma proteins less efficiently and vice versa. Drug half-life defines the time it takes for the concentration or amount of a drug in the body to be reduced by $50 \%$. The greater the half-life of a drug, the longer the drug would stay in the body. For this reason, the half-life determines the doses of drugs (Hossain et al., 2019; Swierczewska et al., 2015; Smalling, 1996; Sarkar et al., 2020c). HERG is a protein in the heart muscle which mediates the rhythm of the heart. HERG can be blocked by many blocking agents. This may lead to the cardiac arrhythmia and sometimes death. Human liver is the primary site of metabolism and it is extremely vulnerable to the harmful effects of various xenobiotic agents. Human hepatotoxicity (H-HT) involves any type of injury to the liver that may lead to organ failure and even death. Ames test is a mutagenicity assay that is 
used to detect the mutagenic chemicals. The mutagenic chemicals can cause mutations and also capable of cancer development. Drug induced liver injury (DILI) is the injury to the liver that are caused by administration of drugs. DILI is one of the reasons that may lead to various liver problems (Sanguinetti et al., 1995; Aronov, 2005; Cheng and Dixon, 2003; Mortelmans and Zeiger, 2000; Holt and Ju, 2006).

In the absorption section, all the ligands performed quite similarly, however, based on the probability values, it can be concluded that 4-hydroxybenzaldehyde and benzoic acid are the best performers of the absorption section. In the distribution section, benzoic acid, bergapten and psoralen showed high plasma protein binding capability and all of the ligands were blood brain barrier permeable. Psoralen should be considered as the best performer in the distribution section, based on the probability values. No ligand showed satisfactory results in the metabolism section. However, 4-hydroxybenzaldehyde, benzoic acid and p-hydroxybenzoic acid showed relatively good results since they were not inhibitory to any of the CYP450 isoenzymes. Benzoic acid could be considered as the best ligand in the metabolism section with good probability values. In the excretion section, 4-hydroxybenzaldehyde is the best ligand with the highest half-life of 1.7 hours. In the toxicity section, both 4-hydroxybenzaldehyde, benzoic acid, p-hydroxybenzoic acid showed the best performances since they were not hERG blockers, human hepatotoxic, Ames mutagenic as well as they were also DILI negative. Bergapten was, however, human hepatotoxic, Ames mutagenic and DILI positive and psoralen was only DILI positive.

The Cytochrome P450 (Cyp450) is a family of enzymes and comprises 57 isoforms of P450 enzymes. These enzymes catalyze the phase-I metabolism of almost $90 \%$ of the marketed drugs and are heme-containing (Glue and Clement, 1999; Tyzack et al., 2014). The functions of these enzymes are to catalyze the conversion of lipophilic drugs to more polar compounds (Danielson, 
2002). Among the 57 isoforms, nine most prevalent isoforms are: CYPs 1A2, 2A6, 2B6, 2C19, 2C8, 2C9, 2D6, 2E1 and 3A4. From the P450 SOM prediction, it can be concluded that all the ligands generated quite sound and similar results.

The Phase pharmacophore perception is a tool of Maestro-Schrödinger Suite 2018-4 that is used in screening of 3D database, pharmacophore modelling and QSAR model development. The engine has 6 types of built-in features and the pharmacophore modelling is mainly carried out based on these 6 types of features: hydrogen bond acceptor (A), hydrogen bond donor (D), negative ionizable $(\mathrm{N})$, positive ionizable $(\mathrm{P})$, hydrophobe $(\mathrm{H})$, and aromatic ring $(\mathrm{R})$. However, the feature number can be increased by customization. The pharmacophore modelling generates a hypothesis which can be used successfully in biological screening for further experiments (Dixon et al., 2006). All the ligand molecules successfully generated the pharmacophore hypotheses. Only psoralen didn't form any bonds with MTB RNA polymerase, however, it generated bonds with the InhA protein. And all other selected ligands formed bonds with both the MTB RNA polymerase and the InhA protein. These hypotheses can be used in various in vitro and in vivo screening of the selected ligand molecules.

All the ligands generated successful solubility results in the solubility test. The acceptable range for $\mathrm{QP} \log \mathrm{PC} 16$ is 4.0 - 18.0, the acceptable range for QPlogPoct is 8.0 - 35.0, the acceptable range for $\mathrm{QP} \log \mathrm{Pw}$ is $4.0-45.0$, the acceptable range for $\mathrm{QP} \log \mathrm{Po} / \mathrm{w}$ is $-2.0-6.5$, the acceptable range for $\mathrm{QP} \log \mathrm{S}$ is $-6.5-0.5$, the acceptable range for CIQPlogS is $-6.5-0.5$ (Hussain and Verma, 2018). Only bergapten gave the QPlogPC16 and QPlogPoct values of 4.392 and 9.129, that are within the acceptable ranges. However, bergapten, benzoic acid, psoralen and p-hydroxybenzoic acid showed QPlogPw values that are within the acceptable range. Moreover, all the ligands showed acceptable values of QPlogPo/w, QPlogS and CIQPlogS. From the solubility test, it can 
be concluded that bergapten showed the best results in the solubility test, with its best scores among all the selected ligand molecules (Table $\mathbf{0 8}$ ).

Frontier orbitals study is an essential method of understanding the pharmacological properties of various small molecules (Matysiak, 2007). HOMO and LUMO are the globally studied orbitals that help to understand the chemical reactivity and kinetic stability of small molecules. The term 'HOMO' indicates the regions on a small molecule that may donate electrons during a complex formation and the term 'LUMO' indicates the regions on a small molecule that may receive electrons from the electron donating species. The difference between HOMO and LUMO energy is known as gap energy. Gap energy corresponds to the electronic excitation energy. The compound that has the greater orbital gap energy, tends to be energetically unfavourable to undergo a chemical reaction and vice versa (Zhan et al., 2003; Hoque et al., 2015). Moreover, the HOMO-LUMO gap also correlates with the hardness and softness of a molecule (Ayers et al., 2006). From the DFT calculations, it was found that bergapten had the lowest gap energy of 0.164 $\mathrm{eV}$ and p-hydroxybenzoic acid had the highest gap energy of $0.298 \mathrm{eV}$. For this reason, bergapten can be considered as the best ligand molecules since it generated the lowest gap energy and it is very likely to undergo a chemical reaction. Moreover, the lowest gap energy also reflects the lowest hardness score of $0.82 \mathrm{eV}$ and highest softness score of $12.190 \mathrm{eV}$. Bergapten also had the highest dipole moment of 7.186 debye and p-hydroxybenzoic acid gave the second lowest dipole moment of 2.524 debyes. For this reason, it can be concluded that, bergapten should be the best ligand and p-hydroxybenzoic acid could be the poorest ligand, among the selected ligand molecules.

From the conducted experiments, two ligands, 4-hydroxybenzaldehyde and bergapten were selected as the best ligands to inhibit MTB RNA polymerase (4-hydroxybenzaldehyde) and MTB 
InhA protein (bergapten), respectively. 4-hydroxybenzaldehyde showed the best results in the docking experiment while inhibiting MTB RNA polymerase (docking score: $-6.062 \mathrm{Kcal} / \mathrm{mol}$ and $\Delta$ GBind Score: $-53.070 \mathrm{Kcal} / \mathrm{mol}$ ) and bergapten generated the best docking results while inhibiting the MTB InhA protein (docking score: $-8.068 \mathrm{Kcal} / \mathrm{mol}$ and $\Delta$ GBind Score: -57.590 $\mathrm{Kcal} / \mathrm{mol})$. In the drug-likeness property experiment, both 4-hydroxybenzaldehyde and bergapten showed fairly good results. In ADME/T test, although, 4-hydroxybenzaldehyde generated one of the best results, however, bergapten showed relatively poor performance in the ADME/T test. In the CYP450 SOM experiment, 4-hydroxybenzaldehyde showed the best results, however, like ADME/T test, bergapten showed poor performance in the CYP450 SOM experiment. On the other hand, in the pharmacophore mapping and modelling, bergapten generated excellent results while inhibiting the InhA protein and 4-hydroxybenzaldehyde also showed quite good result in the pharmacophore modelling experiment while inhibiting MTB RNA polymerase(pharmacophore mapping was not determined). Moreover, in the solubility test and DFT calculation (HOMOLUMO), bergapten showed the best results, however, 4-hydroxybenzoic acid fairly good performances in these experiments. Both 4-hydroxybenzaldehyde and bergapten generated very good results in some aspects, however, in some other aspects they performed poorly. However, both of their performances in all the experiments were good enough to declare then as the ligands among the selected ligands to inhibit MTB RNA polymerase (4-hydroxybenzaldehyde) and the InhA protein (bergapten). Moreover, the docking study had indicated that, both the two selected best ligands are superior to the controls in terms of the docking score and $\triangle$ GBind score of MMGBSA study. 4-hydroxybenzaldehyde had the docking score of $-6.018 \mathrm{Kcal} / \mathrm{mol}$ and rifampicin had the docking score of $-4.813 \mathrm{Kcal} / \mathrm{mol}$. Moreover, 4-hydroxybenzaldehyde had the $\Delta$ GBind score of $-53.070 \mathrm{Kcal} / \mathrm{mol}$, whereas, rifampicin had the $\Delta \mathrm{GBind}$ score of $-34.317 \mathrm{Kcal} / \mathrm{mol}$. 4- 
hydroxybenzaldehyde had the score that were much lower than the scores of rifampicin. On the other hand, Bergapten was selected as the best ligand to inhibit the InhA protein and it was also far superior than the InhA protein inhibitor or control, isoniazid. Isoniazid had docking score of $6.018 \mathrm{Kca} / \mathrm{mol}$ and $\Delta \mathrm{GBind}$ score of $-25.120 \mathrm{Kcal} / \mathrm{mol}$, whereas, bergapten had much lower scores of $-8.068 \mathrm{Kcal} / \mathrm{mol}$ and $-57.590 \mathrm{Kcal} / \mathrm{mol}$, respectively. For this reason, it can be concluded that, both 4-hydroxybenzaldehyde and bergapten had very performance and good efficiency to inhibit TB, when compared to the widely used drugs that are used to treat TB.

The PASS prediction was study was conducted on only these two best ligands to determine their various biological and toxicological effects. ProTox-II server evaluates the toxicity of a chemical compound and classifies the compound into a toxicity class ranging from 1 to 6 . The server classifies the compound according to the Globally Harmonized System of Classification and Labelling of Chemicals (GHS) (36). According to the Globally Harmonized System of Classification and Labelling of Chemicals (GHS), Class 1: fatal if swallowed (LD50 $\leq 5)$, class 2: fatal if swallowed $(5<\operatorname{LD} 50 \leq 50)$, class 3 : toxic if swallowed $(50<\operatorname{LD} 50 \leq 300)$, class 4 : harmful if swallowed $(300<$ LD50 $\leq 2000)$, class 5: may be harmful if swallowed $(2000<$ LD50 $\leq 5000)$ (United Nations. Economic Commission for Europe. Secretariat, 2005). And ProTox-II server adds one more class to the 5 classes, making them 6 classes in total, class VI: non-toxic (LD50 > 5000) (http://tox.charite.de/protox_II/index.php?site=home. Accessed on: 09, August, 2019). The predicted LD50 value of bergapten was $8100 \mathrm{mg} / \mathrm{kg}$ and the toxicity class was 6 . For this reason bergapten is non-toxic. The PASS prediction study was carried out for 10 intended biological activities and 5 toxic effects. Both 4-hydroxybenzaldehyde and bergapten showed good biological activities like aldehyde oxidase inhibitor, CYP2A6 substrate, CYP2A substrate, CYP2E1 substrate and CYP1A2 substrate. However, 4-hydroxybenzaldehyde also showed nitrilase inhibitory 
activity, thioredoxin inhibitory activity and chymosin activity and bergapten also showed activities: HIF1A expression inhibitor and CYP2A11 substrate. The toxic effects showed by 4hydroxybenzaldehyde were: weakness, vascular toxicity and fatty liver and bergapten showed the toxic effects: hypothermic and carcinogenic group 3. These toxic effects may interfere with the successful approval and marketing of the drugs. The PASS prediction study had confirmed the superiority of the two best ligands in the toxicity and adverse effects section. For this reason, it can be declared that, both the two selected agents showed satisfactory performances in the tests when compared to the controls.

\section{Conclusion}

5 agents known to have potential anti-tubercular properties were used to analyse in the experiment. Considering all the parameters, it is clear that, all the plant derived anti-tubercular agents had very good inhibitory activities on the MTB. The various tests of in silico biology, that were used in the experiment, like the molecular docking study, druglikeness property experiment, ADME/T test, pharmacological property analysis, solubility and DFT calculations as well as the PASS prediction study had confirmed that 4-hydroxybenzaldehyde and bergapten were best agents among the selected ligands as well as their superiority over the two commercial, widely used drugs, rifampicin and isoniazid. For this reason, these two agents can be used effectively to fight against tuberculosis. 4-hydroxybenzaldehyde can be acquired from a variety of sources form the nature, like the plant Cinnamomum kotoense and bergapten can be acquired from the plant Fatoua pilosa. For this reason, these plants can be used effectively to treat tuberculosis. Moreover, in nature, a lot of other 
plants can also be found containing these agents. However, more in vivo and in vitro researches should be carried out to finally confirm their activities. Moreover, more researches should be conducted on the other agents to identify their efficacy against TB since they also gave quite good results in the tests carried out in the experiment. Hopefully, this study will help the researchers in identifying the potential anti-tubercular phytochemicals.

\section{Conflict of Interest}

Authors state that they have no conflict of interest among themselves.

\section{References}

Aronov AM. Predictive in silico modeling for hERG channel blockers. Drug Discov Today. 2005;10:149-155.

Ayers PW, Parr RG, Pearson RG. Elucidating the hard/soft acid/base principle: a perspective based on half-reactions. J Chem Phys. 2006;124:194107.

Becke AD. Density-functional exchange-energy approximation with correct asymptotic behavior. Phys Rev A. 1988;38:3098.

Carel C, Nukdee K, Cantaloube S, Bonne M, Diagne CT, Laval F, Daffe M, Zerbib D. Mycobacterium tuberculosis proteins involved in mycolic acid synthesis and transport localize dynamically to the old growing pole and septum. PLoS One. 2014;9:e97148.

Chen FC, Peng CF, Tsai IL, Chen IS. Antitubercular Constituents from the Stem Wood of Cinnamomum kotoense. J Nat Prod. 2005;68:1318-23. 
Chen JJ, Chou TH, Peng CF, Chen IS, Yang SZ. Antitubercular dihydroagarofuranoid sesquiterpenes from the roots of Microtropis fokienensis. J Nat Prod. 2007;70:202-5.

Cheng A, Dixon SL. In silico models for the prediction of dose-dependent human hepatotoxicity. J Comput Aid Mol Des. 2003;17:811-823.

Cheng F, Li W, Zhou Y, Shen J, Wu Z, Liu G, Lee PW, Tang Y. admetSAR: a comprehensive source and free tool for assessment of chemical ADMET properties.

Chiang CC, Cheng MJ, Peng CF, Huang HY, Chen IS. A novel dimeric coumarin analog and antimycobacterial constituents from Fatoua pilosa. Chem Biodivers 2010;7:1728-36.

Daniel TM. The history of tuberculosis. Resp Med. 2006;100:1862-70.

Danielson PB. The cytochrome P450 superfamily: biochemistry, evolution and drug metabolism in humans. Curr Drug Metab. 2002;3(6):561-97.

Dixit B. A review on the effects of CMPF binding with Human Serum Albumin. Bioinformatics Rev. 2017;3(9):9-18.

Dixon SL, Smondyrev AM, Knoll EH, Rao SN, Shaw DE, Friesner RA. PHASE: a new engine for pharmacophore perception, 3D QSAR model development, and 3D database screening: 1. Methodology and preliminary results. J Comput Aid Mol Des. 2006;20:647-71.

Dokorou V, Kovala-Demertzi D, Jasinski JP, Galani A, Demertzis MA. Synthesis, Spectroscopic Studies, and Crystal Structures of Phenylorganotin Derivatives with [Bis (2, 6-dimethylphenyl) amino] benzoic Acid: Novel Antituberculosis Agents. Helv Chim Akta. 2004;87:1940-1950. 
Dong J, Wang NN, Yao ZJ, Zhang L, Cheng Y, Ouyang D, Lu AP, Cao DS. ADMETlab: a platform for systematic ADMET evaluation based on a comprehensively collected ADMET database. J Cheminformatics. 2018;10:29.

Dong Y, Li J, Qiu X, Yan C, Li X. Expression, purification and crystallization of the (3R)hydroxyacyl-ACP dehydratase HadAB complex from Mycobacterium tuberculosis. Protein Expr Purif. 2015;114:115-20.

Drwal MN, Banerjee P, Dunkel M, Wettig MR, Preissner R. ProTox: a web server for the in silico prediction of rodent oral toxicity. Nucleic Acids Res. 2014;42:W53-8.

Ducasse-Cabanot S, Cohen-Gonsaud M, Marrakchi H, Nguyen M, Zerbib D, Bernadou J, Daffé M, Labesse G, Quémard A. In vitro inhibition of the Mycobacterium tuberculosis $\beta$-ketoacyl-acyl carrier protein reductase MabA by isoniazid. Antimicrob Agents Chemother. 2004;48:242-9.

Egan WJ, Merz KM, Baldwin JJ. Prediction of drug absorption using multivariate statistics. Journal Med Chem. 2000;43:3867-77.

Ettehad D, Schaaf HS, Seddon JA, Cooke GS, Ford N. Treatment outcomes for children with multidrug-resistant tuberculosis: a systematic review and meta-analysis. Lancet Infect Dis. 2012;12:449-56.

Filimonov DA, Lagunin AA, Gloriozova TA, Rudik AV, Druzhilovskii DS, Pogodin PV, Poroikov VV. Prediction of the biological activity spectra of organic compounds using the PASS online web resource. Chem Heterocycl Com+. 2014;50:444-57. 
Geronikaki A, Poroikov V, Hadjipavlou-Litina D, Filimonov D, Lagunin A, Mgonzo R. Computer aided predicting the biological activity spectra and experimental testing of new thiazole derivatives. Qsar Comb Sci. 1999;18:16-25.

Ghose AK, Viswanadhan VN, Wendoloski JJ. A knowledge-based approach in designing combinatorial or medicinal chemistry libraries for drug discovery. 1. A qualitative and quantitative characterization of known drug databases. J Comb Chem. 1999;1:55-68.

Glue P, Clement RP. Cytochrome P450 enzymes and drug metabolism-basic concepts and methods of assessment. Cell Mol Neurobiol. 1999;19:309-23.

Grange JM, Zumla A. The global emergency of tuberculosis: what is the cause?. The journal of the Royal Society for the Promotion of Health. 2002;122:78-81.

Guengerich FP. Cytochrome P-450 3A4: regulation and role in drug metabolism. Annu Rev Pharmacol. 1999;39:1-7.

He X, Alian A, de Montellano PR. Inhibition of the Mycobacterium tuberculosis enoyl acyl carrier protein reductase InhA by arylamides. Bioorgan Med Chem. 2007;15:6649-58.

Holt MP, Ju C. Mechanisms of drug-induced liver injury. AAPS J. 2006;8:E48-54.

Hoque MM, Halim MA, Sarwar MG, Khan MW. Palladium-catalyzed cyclization of 2-alkynyl-Nethanoyl anilines to indoles: synthesis, structural, spectroscopic, and mechanistic study. J Phys Org Chem. 2015;28:732-42.

Hossain S, Sarkar B, Prottoy MN, Araf Y, Taniya MA, Ullah MA. Thrombolytic activity, drug likeness property and ADME/T analysis of isolated phytochemicals from ginger (zingiber 
officinale) using in silico approaches. Modern Research in Inflammation. 2019 Aug 31;8(3):2943. DOI: $10.4236 / \mathrm{mri} .2019 .83003$

Hubbard RE, Kamran Haider M. Hydrogen bonds in proteins: role and strength. e LS 2001.

Hussain A, Verma CK. A Combination of Pharmacophore Modeling, Molecular Docking and Virtual Screening Study Reveals 3, 5, 7-Trihydroxy-2-(3, 4, 5-trihydroxyphenyl)-4H-Chromen-4One as a Potential Anti-Cancer Agent of COT Kinase. Indian J Pharm Educ. 2018;52:699-706.

Lee C, Yang W, Parr RG. Development of the Colle-Salvetti correlation-energy formula into a functional of the electron density. Phys Rev B. 1988;37:785.

Li AP. Screening for human ADME/Tox drug properties in drug discovery. Drug Discov Today. 2001;6:357-366.

LigPrep, Schrödinger, LLC, New York, NY, 2018-4.

Lim TK. Hibiscus taiwanensis. In Edible Medicinal and Non Medicinal Plants 2014;381-384.

Lipinski CA, Lombardo F, Dominy BW, Feeney PJ. Experimental and computational approaches to estimate solubility and permeability in drug discovery and development settings. Adv Drug Deliver Rev. 1997; 23:3-25.

Lipinski CA. Lead-and drug-like compounds: the rule-of-five revolution. Drug Discov Today: Technologies. 2004; 1:337-41.

Matysiak J. Evaluation of electronic, lipophilic and membrane affinity effects on antiproliferative activity of 5-substituted-2-(2, 4-dihydroxyphenyl)-1, 3, 4-thiadiazoles against various human cancer cells. Eur J Med Chem. 2007;42:940-7. 
McIlleron H, Wash P, Burger A, Norman J, Folb PI, Smith P. Determinants of rifampin, isoniazid, pyrazinamide, and ethambutol pharmacokinetics in a cohort of tuberculosis patients. Antimicrob Agents Ch. 2006;50:1170-77.

Moin AT, Sakib MN, Araf Y, Sarkar B, Ullah MA. Combating COVID-19 Pandemic in Bangladesh: A Memorandum from Developing Country. Preprints. 2020 May 27. DOI: 10.20944/preprints202005.0435.v1

Molle V, Gulten G, Vilchèze C, Veyron-Churlet R, Zanella-Cléon I, Sacchettini JC, Jacobs Jr WR, Kremer L. Phosphorylation of InhA inhibits mycolic acid biosynthesis and growth of Mycobacterium tuberculosis. Mol Microbiol. 2010;78:1591-605.

Mortelmans K, Zeiger E. The Ames Salmonella/microsome mutagenicity assay. Mutation research/fundamental and molecular mechanisms of mutagenesis. 2000;455:29-60.

Muegge I, Heald SL, Brittelli D. Simple selection criteria for drug-like chemical matter. J Med Chem. 2001;44:1841-6.

Organic Chemistry Portal. https://www.organic-chemistry.org/prog/peo. Accessed on: $\underline{10 / 10 / 2019 .}$

Parr, R. G., \& Yang, W. Density-Functional Theory of Atoms and Molecules, vol. 16 of International series of monographs on chemistry. 1989. Oxford University Press. New York.

Pearson RG. Absolute electronegativity and hardness correlated with molecular orbital theory. PNAS USA. 1986;83:8440-1. 
Pollastri MP. Overview on the Rule of Five. Curr Protoc Pharmacol. 2010; 49:9-12.

Raj U, Varadwaj PK. Flavonoids as multi-target inhibitors for proteins associated with Ebola virus: In silico discovery using virtual screening and molecular docking studies. Interdiscip Sci. 2016;8:132-41.

Rastogi N, David HL. Mode of action of antituberculous drugs and mechanisms of drug resistance in Mycobacterium tuberculosis. Res Microbiol. 1993;44:133-43.

Sahin S, Benet LZ. The operational multiple dosing half-life: a key to defining drug accumulation in patients and to designing extended release dosage forms. Pharm Res. 2008; 15:2869-77.

Sanguinetti MC, Jiang C, Curran ME, Keating MT. A mechanistic link between an inherited and an acquird cardiac arrthytmia: HERG encodes the IKr potassium channel. Cell. 1995;81:299-307.

Sarkar B, Islam SS, Ullah MA, Hossain S, Prottoy MN, Araf Y, Taniya MA. Computational assessment and pharmacological property breakdown of eight patented and candidate drugs against four intended targets in Alzheimer's disease. Advances in Bioscience and Biotechnology. 2019 Nov 25;10(11):405. DOI: 10.4236/abb.2019.1011030

Sarkar B, Ullah MA, Araf Y, Das S, Rahman MH, Moin AT. Designing novel epitope-based polyvalent vaccines against herpes simplex virus-1 and 2 exploiting the immunoinformatics approach. Journal of Biomolecular Structure and Dynamics. 2020 Aug 6:1-21. DOI: $10.1080 / 07391102.2020 .1803969$ 
Sarkar B, Ullah MA, Araf Y. A systematic and reverse vaccinology approach to design novel subunit vaccines against dengue virus type-1 and human Papillomavirus-16. Informatics in Medicine Unlocked. 2020 May 16:100343. DOI: 10.1016/j.imu.2020.100343

Sarkar B, Ullah MA, Islam SS, Rahman MH, Araf Y. Analysis of plant-derived phytochemicals as anti-cancer agents targeting cyclin dependent kinase-2, human topoisomerase IIa and vascular endothelial growth factor receptor-2. Journal of Receptors and Signal Transduction. 2020 Aug 12:1-7. DOI: $10.1080 / 10799893.2020 .1805628$

Sarkar B, Ullah MA, Prottoy NI. Computational Exploration of Phytochemicals as Potent Inhibitors of Acetylcholinesterase Enzyme in Alzheimer's Disease. medRxiv. 2020 Jan 1. DOI: 10.1101/2020.01.04.20016535

Sastry GM, Adzhigirey M, Day T, Annabhimoju R, Sherman W. Protein and ligand preparation: parameters, protocols, and influence on virtual screening enrichments. J Comput Aid Mol Des. 2013;27:221-34.

Schneidman-Duhovny D, Nussinov R, Wolfson HJ. Predicting molecular interactions in silico: II. Protein-protein and protein-drug docking. Curr Med Chem. 2004;11:91-107.

Schrödinger Release 2015-1: Maestro (2015), Schrödinger, LLC, New York, NY.

Sepkowitz KA. How contagious is tuberculosis?. Clin Infect Dis. 1996;23:954-62.

Shah M, Parpio Y, Gul R, Ali A. Educational Needs Of Tuberculosis Patients Based On Their Experiences In Karachi, Pakistan. i-Manager's Journal on Nursing. 2015;5:20. 
Smalling RW. Molecular biology of plasminogen activators: what are the clinical implications of drug design?. Am J Cardiol. 1996;78:2-7.

Sreeramareddy CT, Panduru KV, Verma SC, Joshi HS, Bates MN. Comparison of pulmonary and extrapulmonary tuberculosis in Nepal-a hospital-based retrospective study. BMC Infect Dis. 2008;8:8.

Swierczewska M, Lee KC, Lee S. What is the future of PEGylated therapies?. Expert Opin Emerg Dr. 2015;20:531-536.

Tyzack JD, Mussa HY, Williamson MJ, Kirchmair J, Glen RC. Cytochrome P450 site of metabolism prediction from 2D topological fingerprints using GPU accelerated probabilistic classifiers. J Cheminformatics. 2014;6:29.

Ullah A, Prottoy NI, Araf Y, Hossain S, Sarkar B, Saha A. Molecular Docking and Pharmacological Property Analysis of Phytochemicals from Clitoria ternatea as Potent Inhibitors of Cell Cycle Checkpoint Proteins in the Cyclin/CDK Pathway in Cancer Cells. Computational Molecular Bioscience. 2019 Sep 6;9(03):81. DOI: 10.4236/cmb.2019.93007

Ullah MA, Johora FT, Sarkar B, Araf Y, Rahman MH. Curcumin analogs as the inhibitors of TLR4 pathway in inflammation and their drug like potentialities: a computer-based study. Journal of Receptors and Signal Transduction. 2020 Mar 28:1-5. DOI: 10.1080/10799893.2020.1742741

United Nations. Economic Commission for Europe. Secretariat, 2005. Globally harmonized system of classification and labelling of chemicals (GHS). United Nations Publications. 
Veber DF, Johnson SR, Cheng HY, Smith BR, Ward KW, Kopple KD. Molecular properties that influence the oral bioavailability of drug candidates. J Med Chem. 2002;45:2615-23.

Visualizer, D.S. (2017) Release 4.1. Accelrys Inc., San Diego, CA.

Yuriev E, Ramsland PA. Latest developments in molecular docking: 2010-2011 in review. J Mol Recognit. 2013; 26:215-39.

Zaretzki J, Bergeron C, Huang TW, Rydberg P, Swamidass SJ, Breneman CM. RS-WebPredictor: a server for predicting CYP-mediated sites of metabolism on drug-like molecules. Bioinformatics. 2012;29:497-8.

Zhan CG, Nichols JA, Dixon DA. Ionization potential, electron affinity, electronegativity, hardness, and electron excitation energy: molecular properties from density functional theory orbital energies. J Phy Chem A. 2003;107:4184-95.

Zhang X, Perez-Sanchez, H and C Lightstone F, (2017) A comprehensive docking and MM/GBSA rescoring study of ligand recognition upon binding antithrombin. Curr Top Med Chem. 17;163139.

Zhang Y, Wade MM, Scorpio A, Zhang H, Sun Z. Mode of action of pyrazinamide: disruption of Mycobacterium tuberculosis membrane transport and energetics by pyrazinoic acid. $\mathrm{J}$ Antimicrob Chemoth. 2003;52:790-5.

Zoete V, Grosdidier A, Michielin O. Docking, virtual high throughput screening and in silico fragment-based drug design. J Cell Mol Med. 2009;13:238-48. 